\title{
On the Commissura transversa Halleri in Cyprinoids.
}

\author{
By \\ Naokichi Suzuki. \\ (Department of Anatomy, Manchuria Medical College, Mukden.)
}

With 25 'Text-figures.

This information aims to get the accurate analysis of the constitutional elements of the commissura transversa in cyprinoids and also to establish the intimate relation with its correlative area, unifying some of the older findings, and adding some which I believe are new. Some questions are untouched in this observation, but still they can probably be settled by further investigation in the various specimens of teleosts.

For this present research, the brain of the adult specimens of - certain cyprinoids (Cyprinus carpio, Carassius carassius and Carassius auratus) were employed. All of the serial microscopic preparations were made in the frontal, horizontal or the sagittal sections, and stained by the various methods, such as Weigert-Pal, Weigert-Pal-vitalscharlach VIII, Pal-carmine, Bielschowsky, Cajal, Golgi, Nissl, Van Gieson, thionin, and hematoxylin-eosin.

At the outset, it is a great pleasure to me to tender my thanks to Director Prof. K. Kudo, for suggesting this subject, as also for his constant advice and encouragement throughout the work.

\section{Commissura transversa.}

The transition of this commissure over the medial plane lies directly ventral to the commissura supraoptica (dorsalis). between both of the

1) Cf. Kudo, K. und Suzuki, N., Über die Comm. transversa bei Ophicephalus argus Cantor. Psychiatrische en Neurologische Bladen, Jaargang 1934, No. 3 en 4. 
lateral optic roots which are estranged with each other. Now, the fibers of this commissure run in bundles latero-dorsally and adjoin the lateral optic root, passing along the ventro-lateral margin of the tr. strio-thalamicus et -hypothalamicus, or through the dorso-medial acellular area of the frontal segment of the nucleus praerotundus (nucleus transversus of Franz ${ }^{1)}$ with the fibers of the tr. tubero-dorsalis, ${ }^{2)}$ and the fibers from the nucleus praerotundus, ${ }^{3}$, which will respectively be explained later on (Fig. 1). The latter, additional fibers are almost undistinguishable

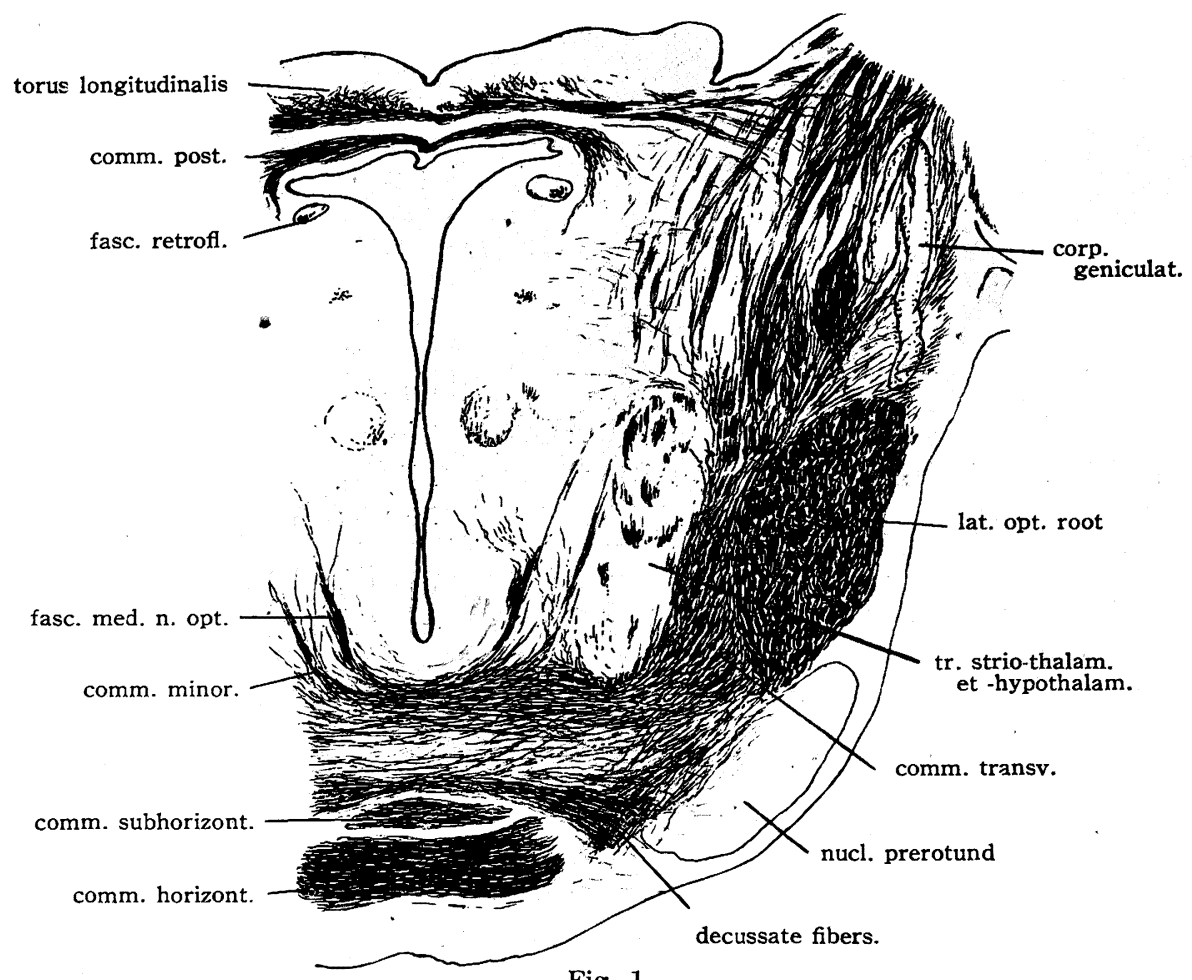

Fig. 1.

A transverse section from Cyprinus carpio, through the medio-frontal segment of the commissura horizontalis and the corpus geniculatum.

from the former, but most of them probably enter the commissura transversa, while the others disappear in the paratransversal area which occupies the medial fibrillar part of the commissura transversa in the torus semicircularis.

1) Franz, V., 1912, p. 433.

2) Brickner, R. M., 1929, p. 277.

3) Franz, V., and also Holmgren, N., 1920, p. 282. 
This united fiber bundle,.composed of fibers of the diagonal course from ventro-medial to dorso-lateral (comp. Fig. 10), entirely elongates dorsally along the medial side of the lateral optic roots, and attains the ventro-medial sphere of the most caudal segment of the nucleus intermedius of Goldstein.

Caudally, the fibers of this commissure changes its course from fronto-medial to caudo-lateral. With the gradual reduction in size and prominence of the nucleus praetectalis, this bundle disappears between the latter nucleus and the lateral optic root. In this level, this fiber bundle is separated from the ventral tectum tongue by the occurrence of the united fiber bundle of the tr. isthmo-tectalis et -praetectalis. More caudally, the fiber course of this commissure with the latter tract expands its lateral and latero-dorsal side, facing the medial side of the tectum tongue, and then it gradually expands near the subependymal layer of the tectum (Fig. 2). The outside of the fiber course of the commissura

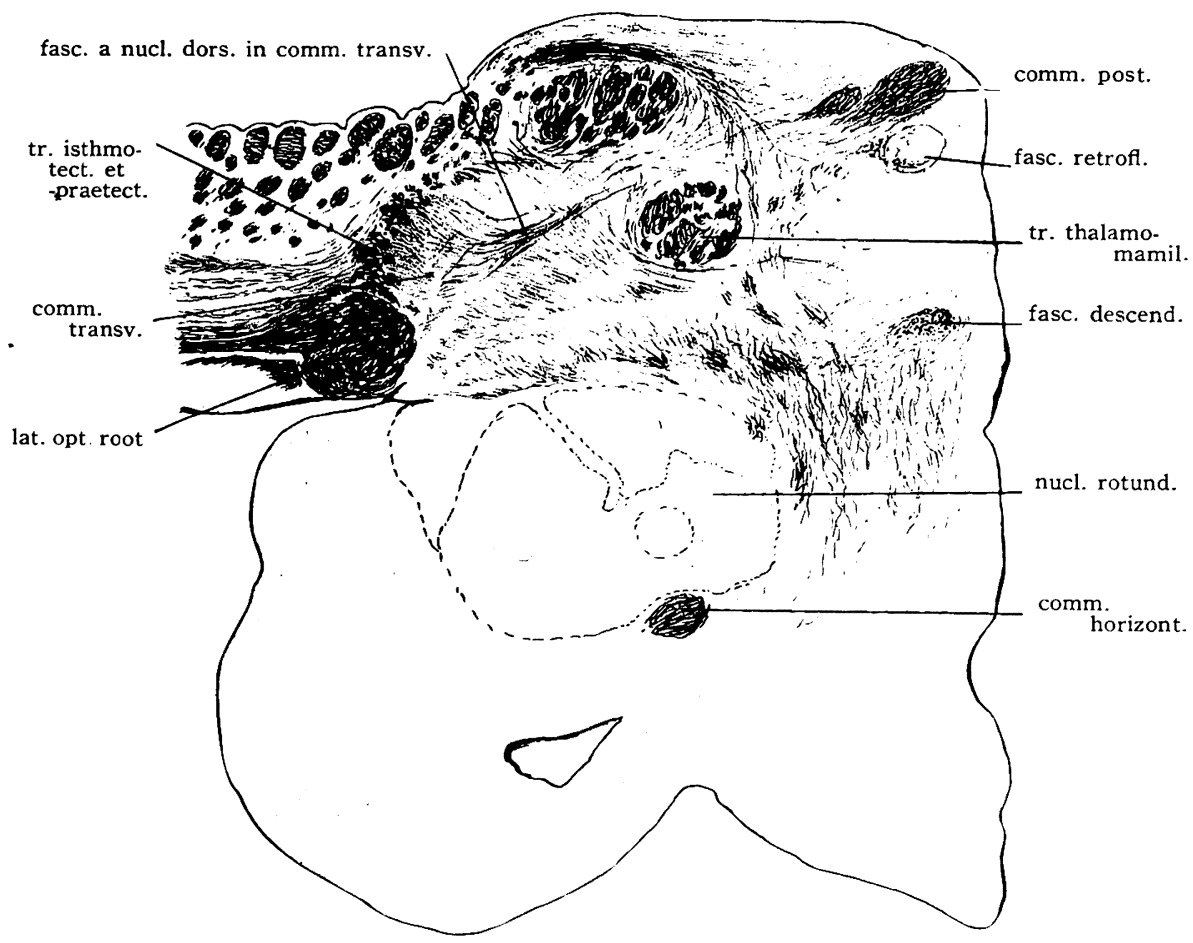

Fig. 2.

A transverse section from Cyprinus carpio, through the posterior segment of the comm. posterior, showing the caudal portion of the commissura transversa. 
transversa in the ventro-lateral limiting area of the stratum zonale of torus semicircularis of Mayser ${ }^{1)}$ is always protected by the thick, wellmedullated fibers of the $\mathrm{tr}$. isthmo-tectalis et -praetectalis."

The actual course of the commissura transversa in the "stratum zonale" of torus semicircularis generally agrees with the descriptions of many authors, excepting the correlation with the other fiber paths.

\section{The fibers which are united with the commissura transversa, or which have the own ending or origin in the torus semicircularis.}

1) The fiber groups of the tr. tubero-dorsalis of Goldstein.

In the direct caudal plane of the fronto-medial commissural part of the commissura transversa or direct dorsal to the comm. horizontalis, the

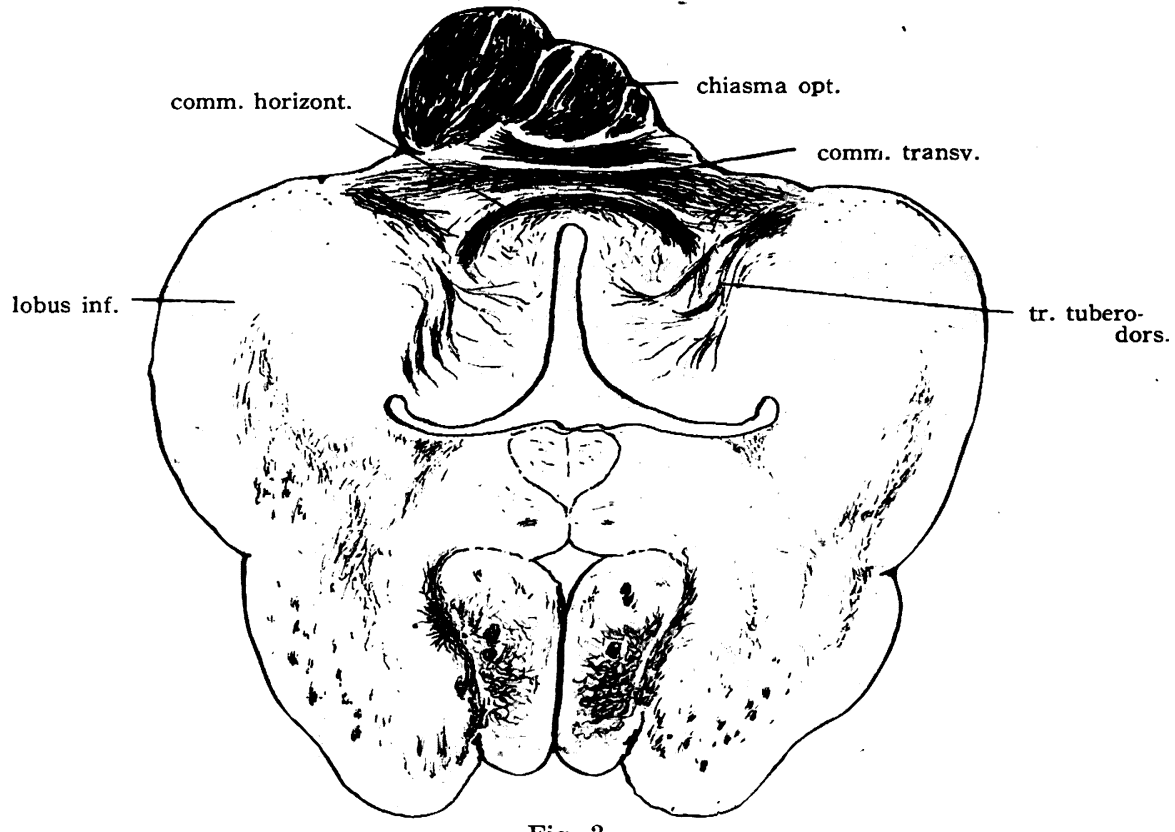

Fig. 3.

A horizontal section from Cyprinus carpio, through the lobi inferiores, showing the tr. tubero-dorsalis, comm. horizontalis and the comm. transversa.

fine medullated commissure which corresponds to the commissura sub-

1) Mayser, P., 1881, p. 342.

2) Kudo, K., 1923, pp. 76-78. and also $\mathrm{J}$ ansen, J., 1929, p. 8. 
horizontalis of Holmgren, ${ }^{1)}$ and a feeble decussation can be observed (Fig. 1). Somewhat ventro-lateral to the above-mentioned fiber bundle, the remarkable fiber groups of the tr. tubero-dorsalis of Goldstein come in sight. This tract is generally well known on its origin, but the further destination is as yet obscure. Lately, Brickner ${ }^{2)}$ evidently described the commissuration of this tract, but the fibers of this tract never transit in the median plane, while, on the contrary, it always leaves in its own side (Fig. 3) (comp. Fig. 12 and 14).

After these fiber bundles have converged frontally, they successively unite with the decussate fibers of the above-mentioned fiber bundle i.e. the comm. subhorizontalis and the feeble fiber decussation. Now, it runs lateral- and then caudalwards making an arch-shaped fiber course along the ventral margin of the tractus strio-thalamicus et -hypothalamicus.

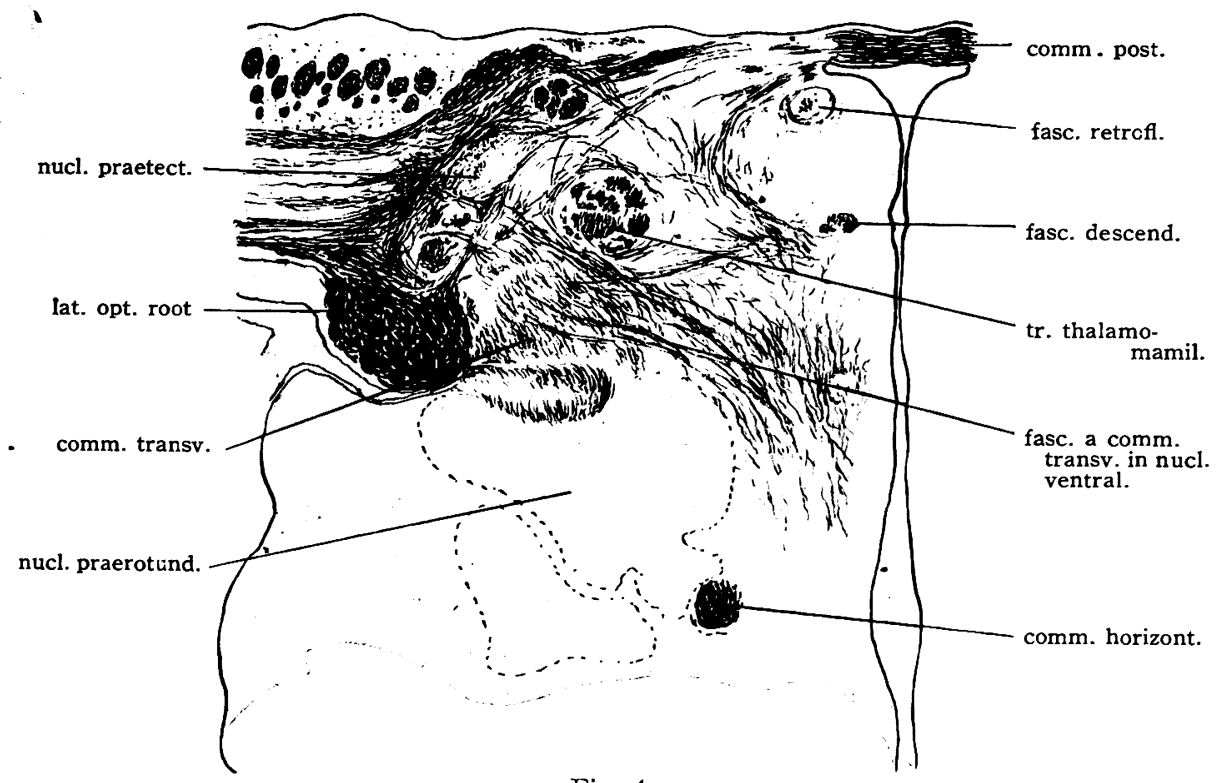

Fig. 4.

A transverse section from Cyprinus carpio, through the comm. posterior, showing the fasciculi a commissura transversa in nucleum ventralem of Brickner.

This united fiber bundle runs dorso-laterally passing through the narrow space between the tr. strio-thalamicus et -hypothalamicus and the nucleus praerotundus which is situated at the ventro-lateral margin, and

1) Holmgren, N., 1920, p. 278 and p. 271 (Fig. 77).

2) Brickner, R. M., 1929, p. 277. 
enters the chief course of the commissura transversa. The fibrillar mixture of both fiber bundles, as was already noted, cannot clearly be distinguished from each other. In this caudal course of the tr. tubero-dorsalis it may, at least, receive a small number of fibers from the nucleus praerotundus. Caudally, the fibers of this tract take the same destination with the comm. transversa and finally transit in the fibrillar intricacy of the torus semicircularis.

2) Fasciculi a commissura transversa in nucleum ventralem of Brickner. ${ }^{\text {) }}$

In the most caudal segment of the nucleus anterior thalami, a number of thin, lightly medullated fibers which arise from the pars venitro-lateralis

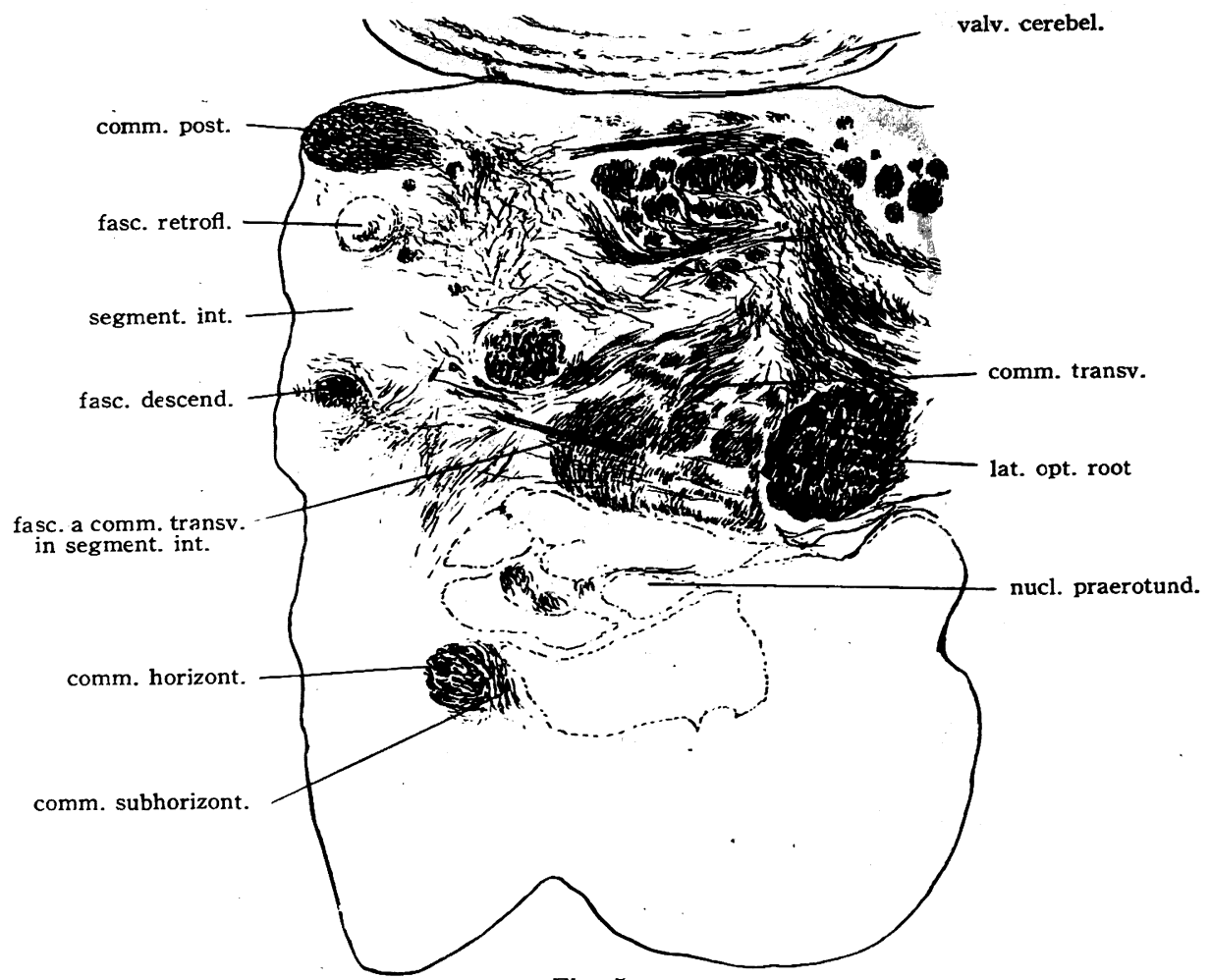

Fig. 5. a

A transverse section from Cyprinus carpio, through the caudal segment of the comm. posterior, showing the fasciculi a comm. transversa in segmentum internun.

of the nucleus tegmenti motorius ventralis loosely stream laterally with

1) Brickner, R. M., 1929, pp. 267-269. 
the feeble fibers from the fasciculus descendens, and then enter the dorso-medial part of the comm. transversa (Fig. 4). The further path of this fascicle probably associates with the commissura transversa having nothing to do with the commissuration itself.

3) Fasciculi a commissura transversa in segmentum internum of Brickner. ${ }^{1}$

The fairly fine, lightly medullated fibers which emerge from the ventro-lateral tongue of the seginentum internum of $\mathrm{B}$ rickner run ventrolaterally and soon enter the dorso-medial part of the comm. transversa (Fig. 5a and also Fig. 7). For a short distance, a greater part of this

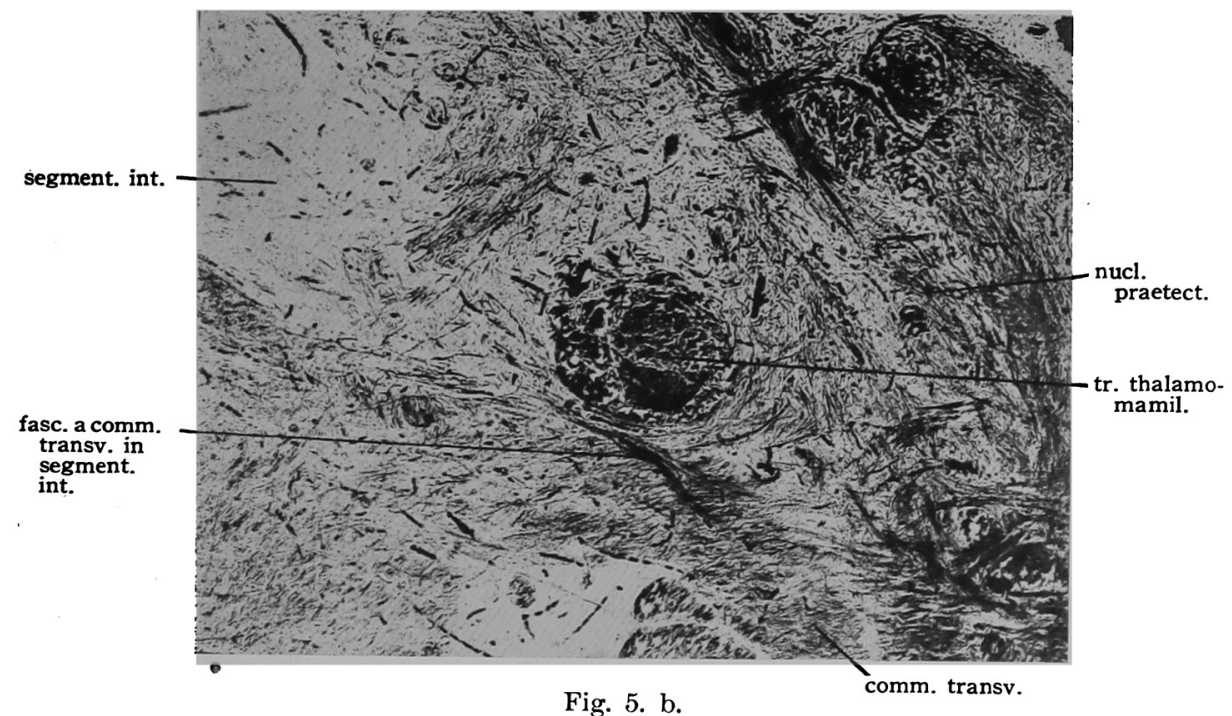

Photomicrograph of a transection from Cyprinus carpio, through the fasciculi a comm. transversa in segmentum internum.

facicle diagonally cuts the fiber course of the latter, but soon takes up the similar stream of fibers, whereas a small number of fibers curves somewhat laterally to the nucleus praetectalis (Fig. 5b).

4) Fasciculus a nucleo dorsali in comm. transversam.")

This fascicle can be classified into two fiber groups which respectively have their own roots in the nucleus tegmenti motorius dorsalis of

1) Brickner, R. M., 1929, p. 241.

2) Brickner, R. M., 1929, pp. 248-249. 
Brickner. The fibers which arise in the dorso-lateral cell group of this nucleus appear more frontally (Fig. 6), than those in the ventrolateral cell group. Both of these bundles are composed of the fine, light brown coloured fibers in Weigert-preparations and always stream from dorso-medial to ventrolateral, piercing the acellular gray between the tr.

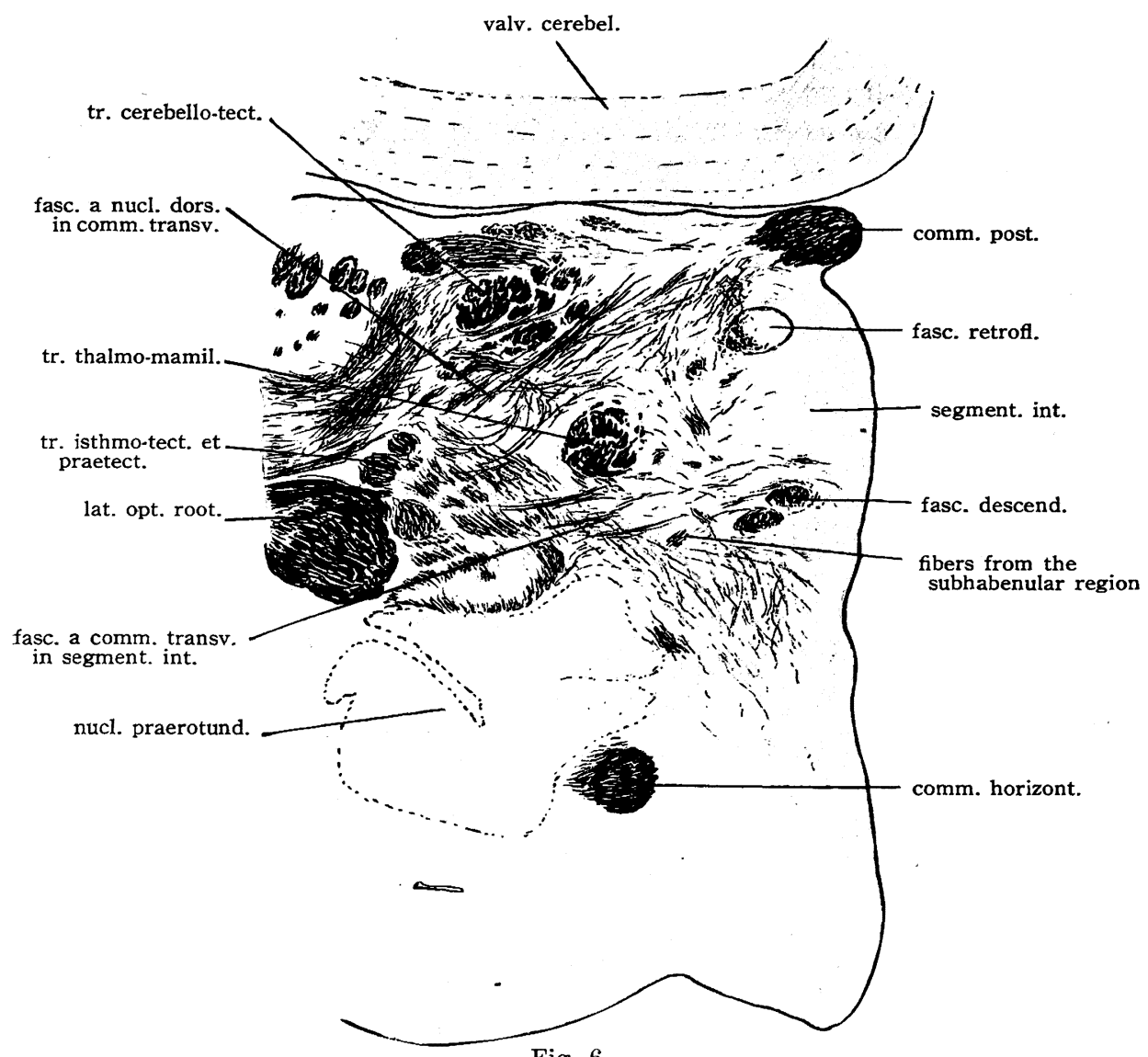

Fig. 6.

A transverse section from Cyprinus carpio, through the caudal segment of the comm. posterior, showing the fasciculus a nucleuo dorsalis in comm. transversa.

cerebello-tectalis and the most caudal segment of the nucleus anterior thalami. The dorsal group of fibers, just mentioned above, is always accompanied with a number of fibers which arise in the comm. posterior as shown by Brickner. ${ }^{1)}$ Thus, these fiber bundles enter the loop of

1) Brickner, R. M., 1929, pp. 248-249. 
the commissura transversa and certainly take the same course with the latter. This fiber bundle seems to be related to the pars isthmica comm. posterioris of $\mathrm{Kudo}{ }^{1)}$

5) Shortly frontal to the above-mentioned tract the feeble fibers emerge from the lateral cell group of the nucleus teginenti motorius dorsalis of Brickner and run ventro-laterally into the direct caudal plane of the pars lateralis nuclei praetectalis. Then, this fiber bundle unites with the dorsal part of the commissura transversa.

6) Fiber bundles which enter the ventral tectum tongue from the comm. transversa.

In the direct caudal plane of the pars lateralis nuclei praetectalis, numerous fiber bundles ascend dorso-laterally, passing through the fiber group of the tr. isthmo-tectalis et -praetectalis near the ventral tectum

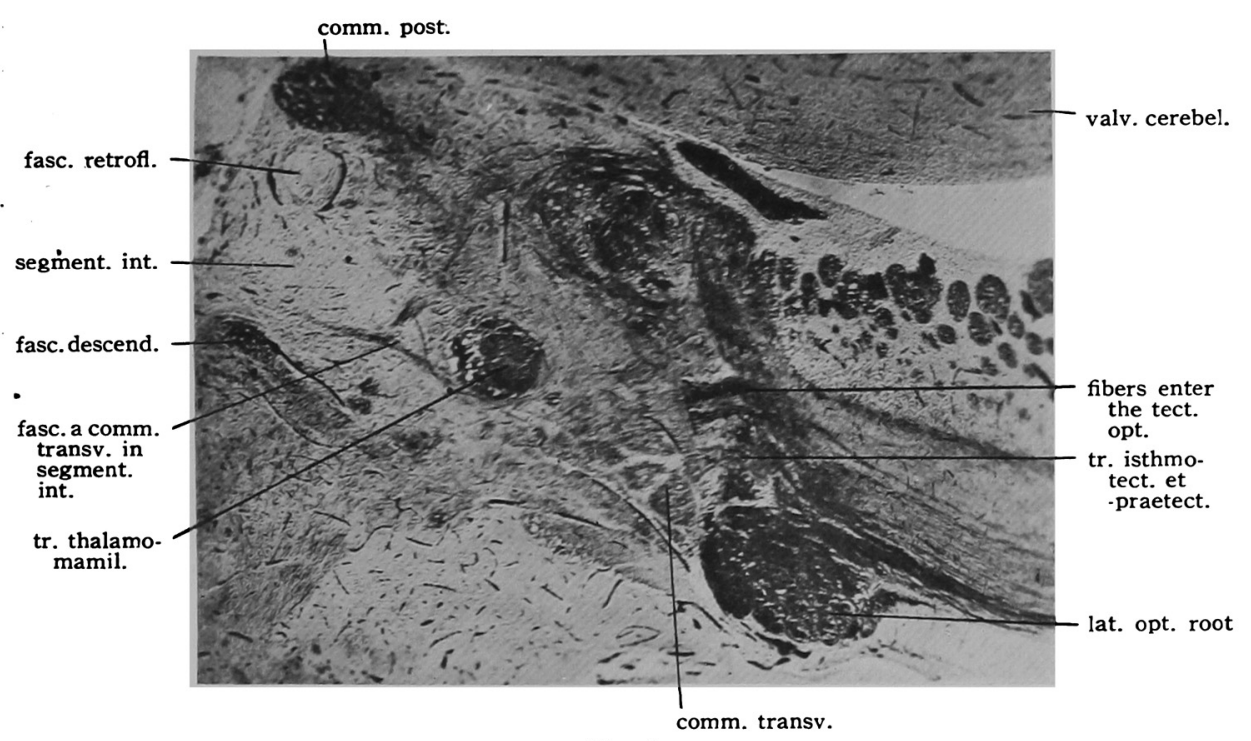

Fig. 7.

A transverse section from Cyprinus carpio, through the caudal segment of the comm. posterior, showing the fiber bundles which enter the ventral tectum tongue from the comm. transversa.

tongue, and disperse in the deep medullary layer and also in the superficial layer of the tectum opticum (Fig. 7). The direction of this course, however, is as yet unable to be established: whether it is tecto-fugal or

1) Kudo, K., 1923, pp. $76-78$. 
tecto-petal, though Mayser ascertained this fiber to be the tecto-fugal bundle. ${ }^{1)}$

7) Tractus isthmo-tectalis and tr. isthmo-praetectalis; pars isthmica commissurae posterioris.

The former noted, two fiber bundles generally accord with the exact description of $\mathrm{Kudo.}$.) The intimate relation with the commissura transversa has been stated in the chapter of the commissura transversa.

8) Tractus tecto-praerotundus.

This tract was first described by $\mathrm{Kudo.}{ }^{3}$ ' It, however, appears somewhat obscure in this specimen, so that the fibers stream dorso-

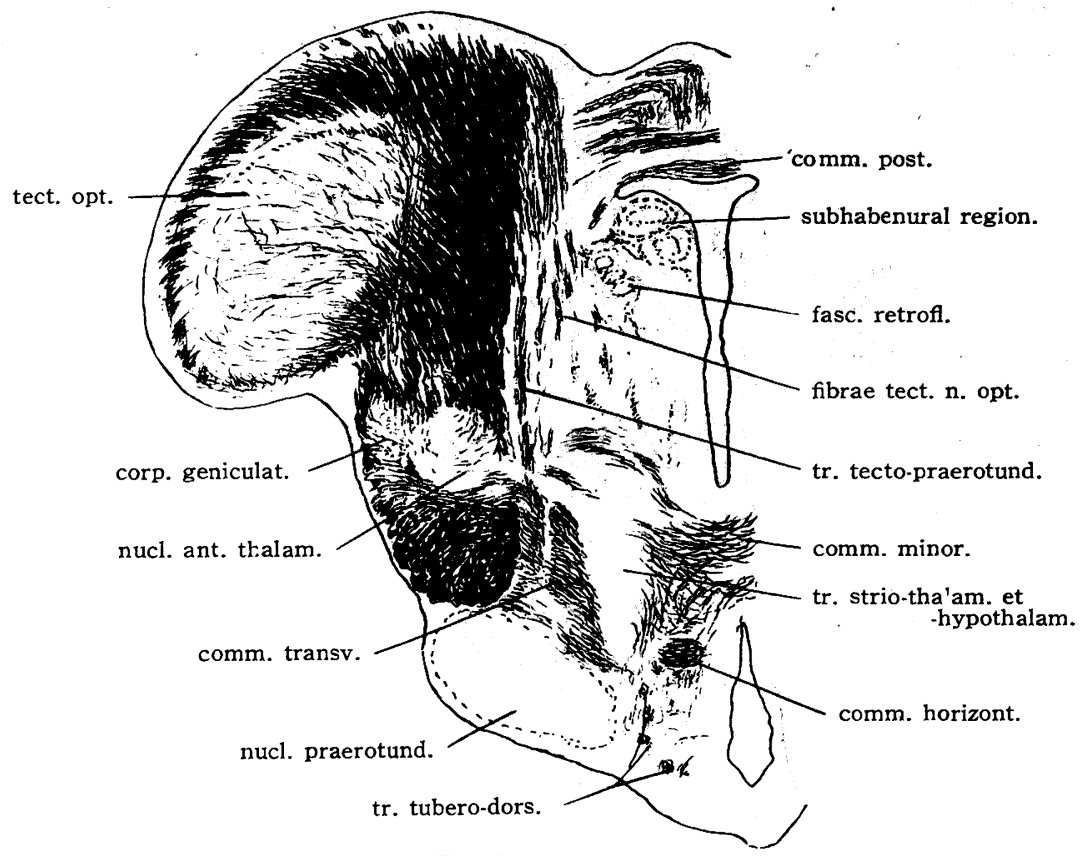

Fig. 8 .

A transverse section from Carassius auratus, through the frontal segment of the nucleus anterior thalami, showing the tr. tecto-prae"otundus.

ventrally or vertically between the medial optic root and the fibrae tectales nervi optici, and then reach the points where the ascending fibers of the

1) Mayser, P., 1881, p. 351.

2) Kudo, K., 1923, pp. 71-78.

3) Kudo, K., 1923, pp. 68-71. 
comm. minor and the comm. supraoptica (dorsalis) enter the medial side of the praetectal region. Then, the fibers of this bundle enter the commissura transversa and perhaps have nothing to do with the nucleus praerotundus (Fig. 8). The further destination of this fiber bundle, however, cannot be ascertained in this specimen.

\section{The fibers which have only the spatial relation with the commissura transversa.}

1) Commissura supraoptica (dorsalis).

This fiber bundle apparently crosses the median plane directly caudal to the chiasma opticum and lies under the ventricle almost at the same height as the fronto-medial portion of the commissura transversa. This bundle is composed of the very fine, inedullated fibers and yet has the considerable grayish colour in Weigert-preparations (Fig. 9).

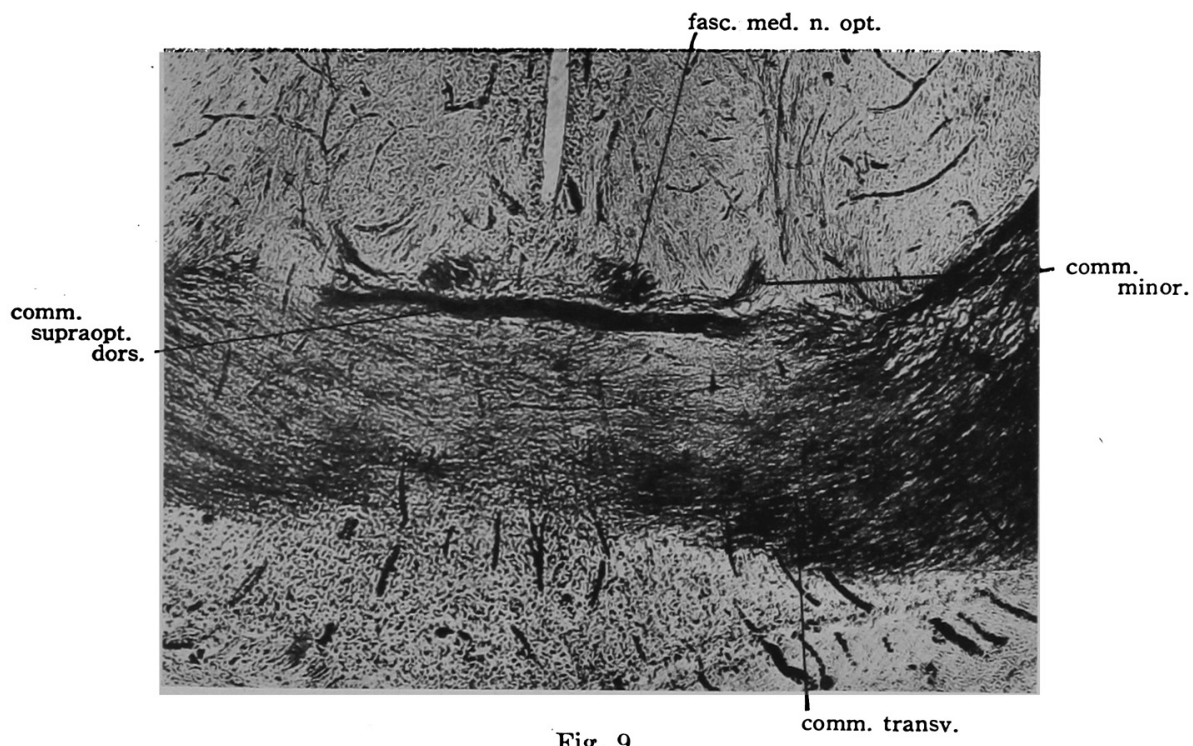

Fig. 9.

Photomicrograph of the medio-frontal segment of the comm. supraoptica (dorsalis) from Cyprinus carpio.

Now, this fiber bundle runs laterally and ventrally to the tr. striothalamicus et -hypothalamicus, and then dorso-laterally. More caudally, this bundle enters between both of the medial and lateral optic roots. A small number of fibers which separate from the actual bundle run 
dorso-laterally over the tr. strio-thalamicus et hypotbalamicus with the commissura minor. Afterwards, this fiber group enters the praetectal region shortly caudal to the actual fiber course of the commissura supraoptica.

This united fiber bundle, then, reaches the ventral sphere of the nucleus anterior thalami (Fig. 10), and also enters the ventral sphere of

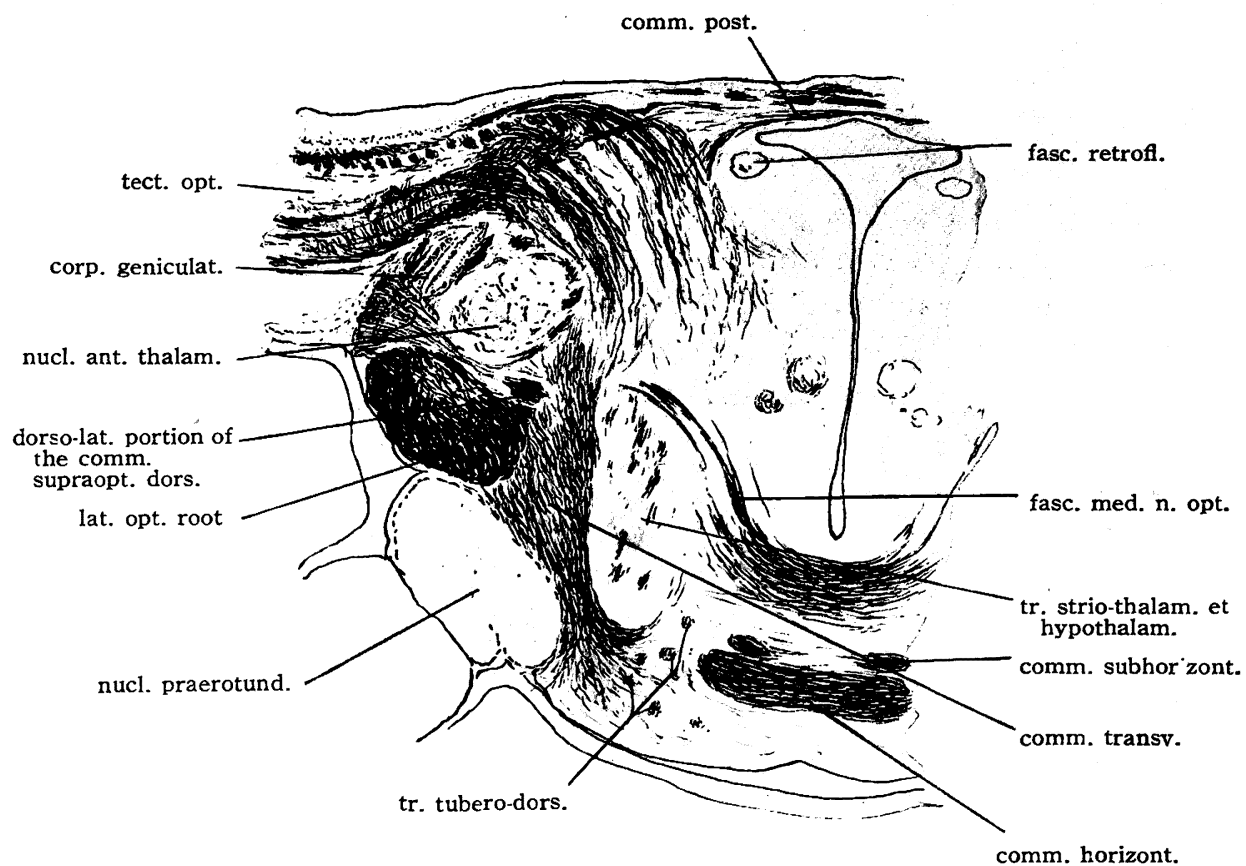

Fig. 10 .

A transverse section from Cyprinus carpio, through the medio-frontal segment of the comm. horizontalis, showing the entrance of the dorso-lateral portion of the comm. supra-optica dorsalis to the praetectal region.

the acellular gray of the pars medialis nc. praetectalis which lies between the nucleus anterior thalami and the ventral tectum tongue (Fig. 11).

In the praetectal region, this fiber bundle cannot well be separated into two groups by the wedge of the pars medialis nc. praetectalis as shown in Ophicephalus argus Cantor. ${ }^{1)}$ But some of them apparently end in the pars medialis and the others elongate to the pars lateralis nc. praetectalis.

The occurrence of the comm. intergeniculata, can scarcely be traced

1) Kudo, K. and suzuki, N. 1934. 


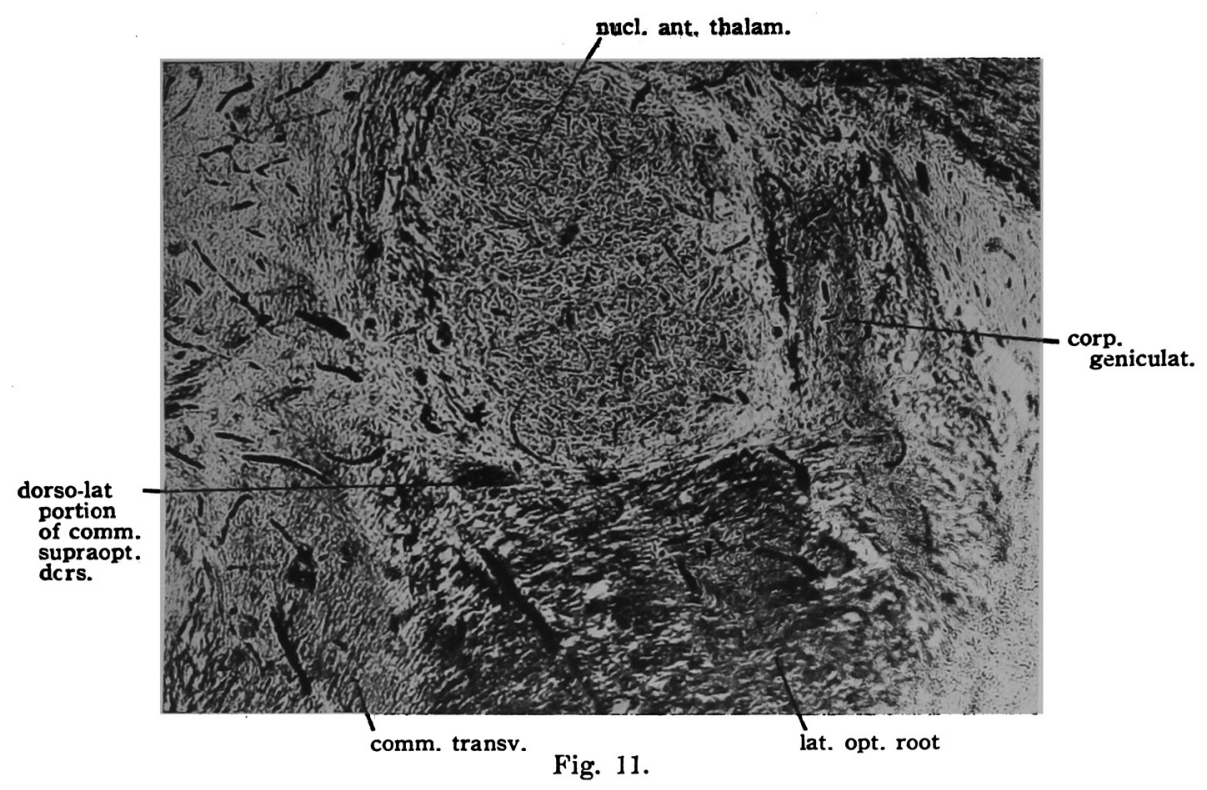

Photomicrograph of the transection of the dorso-lateral portion of the comm. supraoptica dorsalis from Cyprinus carpio.

in the base of the pars medialis nc. praetectalis, being confused with the fibers of the actual fiber bundle of the commissura supraoptica.

\section{2) Commissura minor of Herrick.}

The medio-frontal segment of this commissure lies on the direct dorsal niveau of the frontal part of the comm. transversa or just caudal to the coinm. supraoptica (comp. Figs. 1 and 9). Some exchange of fibers of these latter two bundles can be noticed. The lateral ascending fibers of this commissure take the usual course. A small number of this bundle disappear in the thalamus region, while most of them enter the ventral margin of the nucleus anterior thalami with the small part of the commissura supraoptica dorsalis. Further caudal course of this commissure is unable to be ascertained.

3) Fasciculus medialis n. optici.

The two fiber bundles which are quite separated from the start run, for a short distance, caudally lying on each side on the direct dorsal plane of the fiber plate under the ventricular base (Fig. 9). Caudally, each of them ascends dorso-laterally in a curved arc over the tr. striothalamicus et -hypothalamicus, and then reaches the inedio-ventral margin 
of the nucleus anterior thalami together with the fibers of the just mentioned bundle.

4) Commissura horizontalis Fritsch.

This thick, well-medullated fiber bundle takes the transversal course in the tuber cinereum direct ventro-caudal to the comm. transversa. The slightly medullated, narrow fiber bundle lies directly on this actual thick commissure in Cyprinus carpio (Fig. 1) and, on the contrary, directly under the latter commissure in Carassius carassius and Carassius auratus (Fig. 12). This fine medullated fiber bundle certainly corresponds

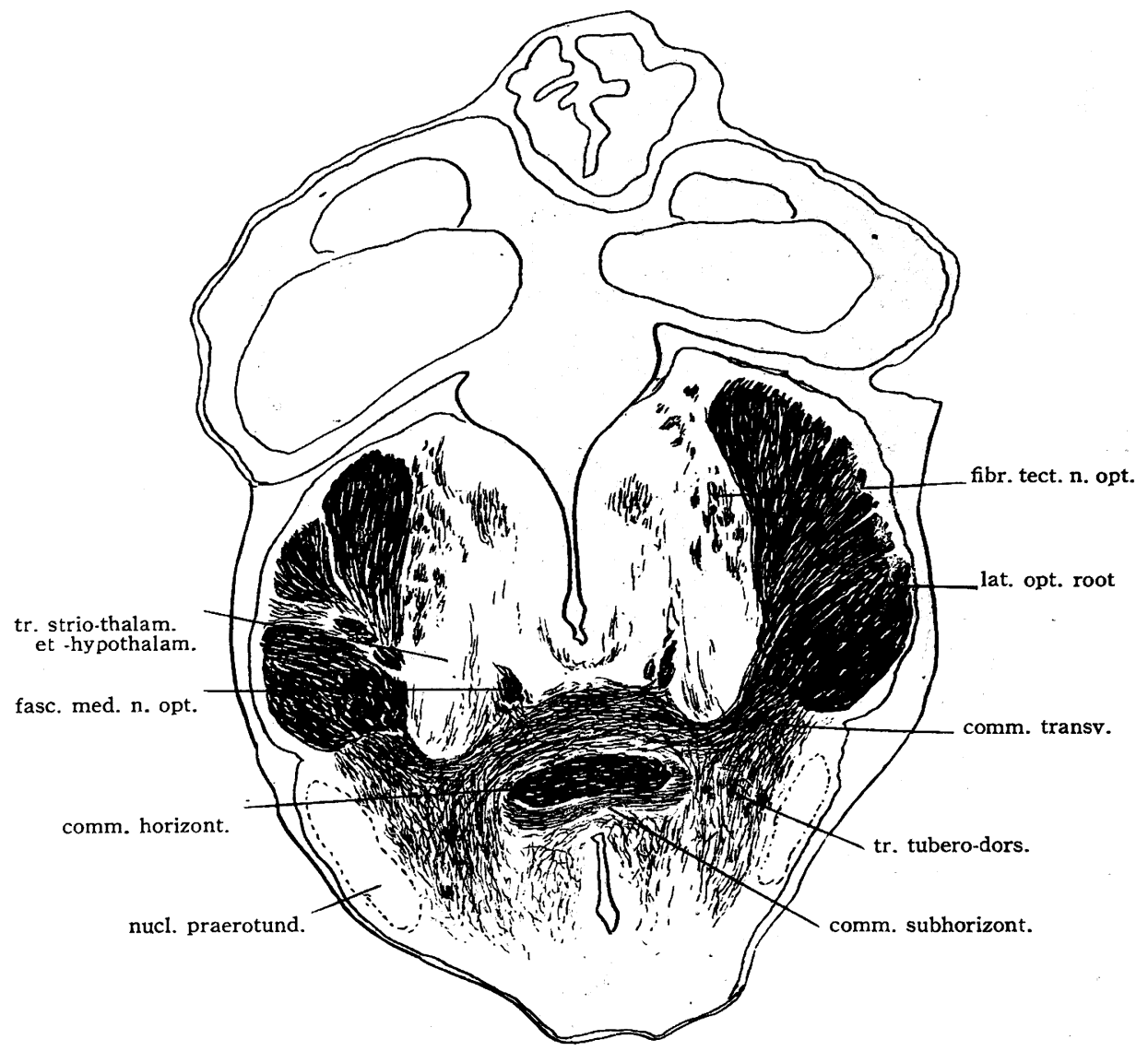

Fig. 12.

A transverse section from Carassius carassius, through the medio-frontal segment of the comm. horizontalis Fritsch.

to the comm. subhorizontalis of Holmgren, although the latter commissure was noticed by Holmgren lying under the comm. transversa in Callionymus 
lyra. More caudally, this united large fiber bundle elongates dorsolaterally with a looped fiber path, until it changes its course into the vertical direction. The thin fibers which correspond to the comm. subhorizontalis, after a short distance, leave the comm. horizontalis and run ventro-laterally along the basal sphere of the nucleus rotundus proprius of Goldstein, and finally vanish in the lobus lateralis.

After the bundle of the comm. horizontalis sagittally has passed through the ventro-lateral area of the nucleus rotundus proprius of Goldstein, it projects between the latter nucleus and the rrucl. paraentopeduncularis of Brickner. The chief part of this bundle unites with the tr. cerebello-tectalis (Fig. 13) and the others are lost in the cellular area around the tr. cerebello-tectalis. Midway in its vertical course, it

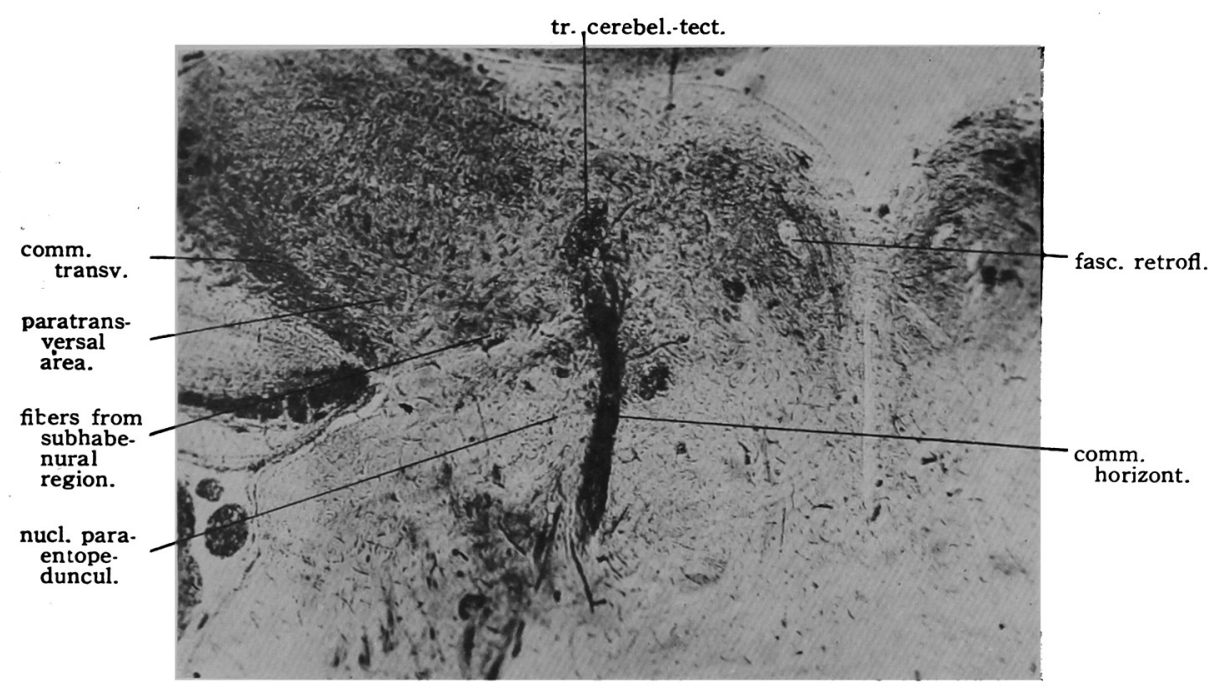

Fig. 13.

A transverse section from Cyprinus carpio, at the point where the ascending fiber bundle of the comm. horizontalis meets with the tr. cerebello-tectalis.

connects with the cerebellar fiber path in the lobus lateralis as mentioned by Mayser. ${ }^{1}$

But it is impossible to trace the further course of small number of fibers to the corpus geniculatum or the tectum opticum as shown by Goldstein. Presumably, there may be no direct connection with the comm. transversa, excepting with the spatial relation in the most frontal segment of the latter commissure.

1) Mayser, P., 1881, p. 331 . 


\section{The fibers which, for a short distance, connect with or simply pass through the commissura transversa.}

There are numerous slightly thin, medullated fiber bundles which pass through the commissura transversa at various heights. So, the comparatively distinct and well known fiber bundles would be described as follows.

1) Tractus geniculo-hypothalamicus of Franz.

In the plane where the comm. horizontalis Fritsch streams dorsocaudad to the nucleus rotundus proprius of Goldstein from the ventral region, the thin fiber bundle of the tr. geniculo-hypothalamicus leaves the corpus geniculatum and runs under the ventral tectum tongue and then takes the horizonto-caudal course passing through the caudal portion of the commissura transversa (in the sagittal sections of Carassius carassius (Fig. 14) and also in the horizontal sections of Cyprinus carpio (Fig.

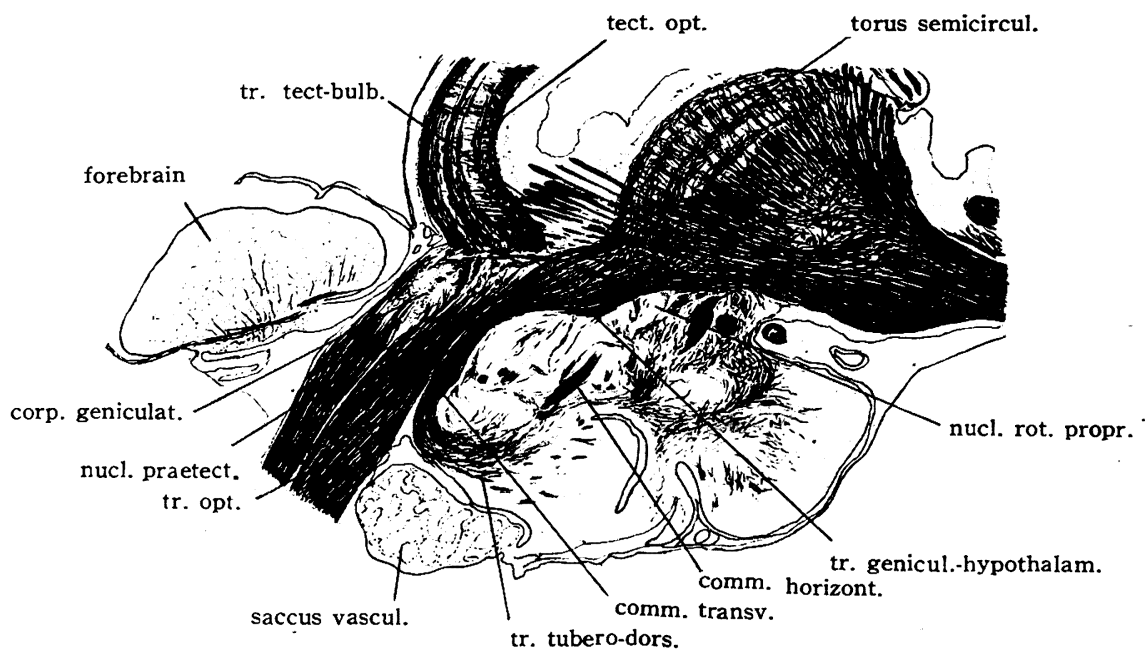

Fig. 14.

A sagittal section from Carassius carassius, through the
middle segment of the corpus geniculatum, showing the tractus geniculo-hypothalamicus of Franz.

15)). Soon this fiber bundle changes its course ventro-medially and sticks out from the thick fiber course of the comm. transversa to reach the dorso-medial part of the nucleus rotundus proprius of Goldstein. The 
caudal part of this tract, then, runs ventrally along the medial zone of the latter nucleus and disperses in the dorso-medial region of the recessus

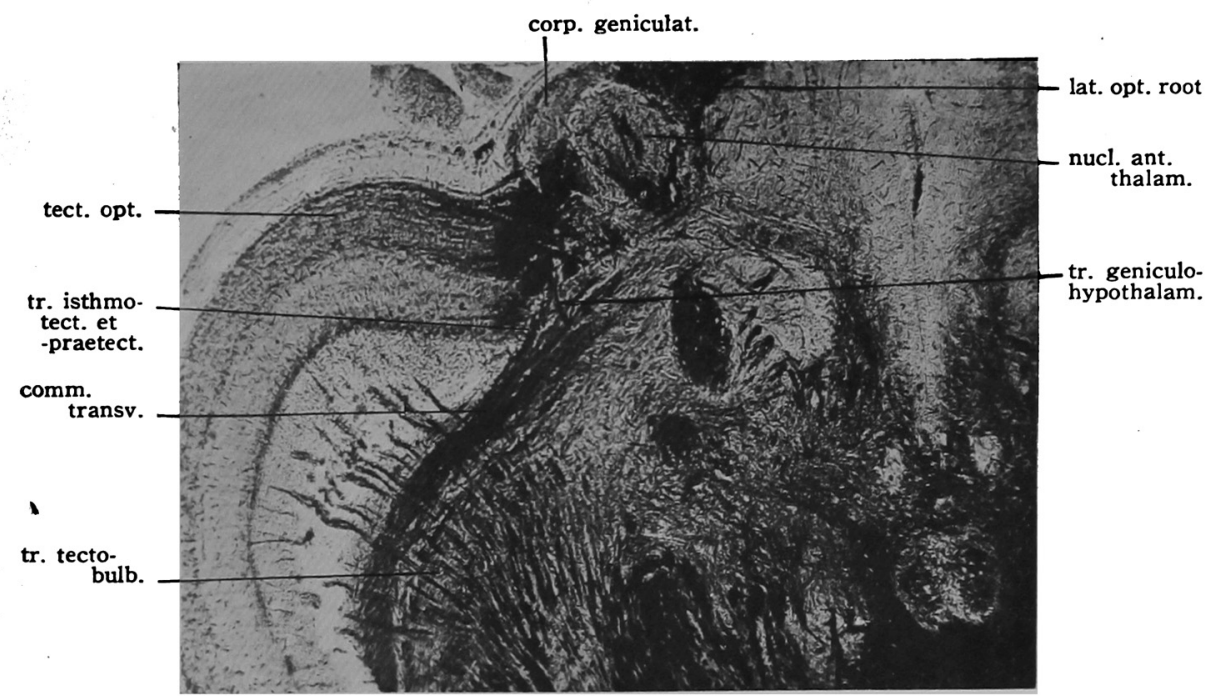

Fig. 15 .

\begin{abstract}
A horizontal section from Cyprinus carpio, through the middle segment of the nucleus anterior thalami, showing the tr. geniculo-hypothalamicus of $\operatorname{Franz}$.
\end{abstract}

lateralis lobi inferioris. It, however, is unable to assume its endstation in the nucleus interpeduncularis as shown by Franz. ${ }^{1)}$

2) Tractus geniculo-myelencephalicus of Holmgren. ${ }^{2)}$

Almost in the same plane where the above-described tract begins to leave the praetectal region, this thin fiber bundle appears in the lateral optic root piercing the latter medioventrally (Fig. 16). This fiber bundle traverses in the comm. transversa with the same course and comes in sight in the most ventral margin of this commissure. More caudally, this tract vanishes in the thick fiber bundle of the tractus tecto-bulbaris cruciatus, so that the further course of this tract and its final endstation in th medial gray of bulb cannot be traced.

3) Tractus tecto-bulbaris.

This tract takes the typical course as shown by Ariëns Kappers ${ }^{3)}$

1) Franz, V., 1912, p. 438.

2) Holmgren, N., 1920, p. 225.

3) Ariëns Kappers, C. U., 1921, p. 817. 


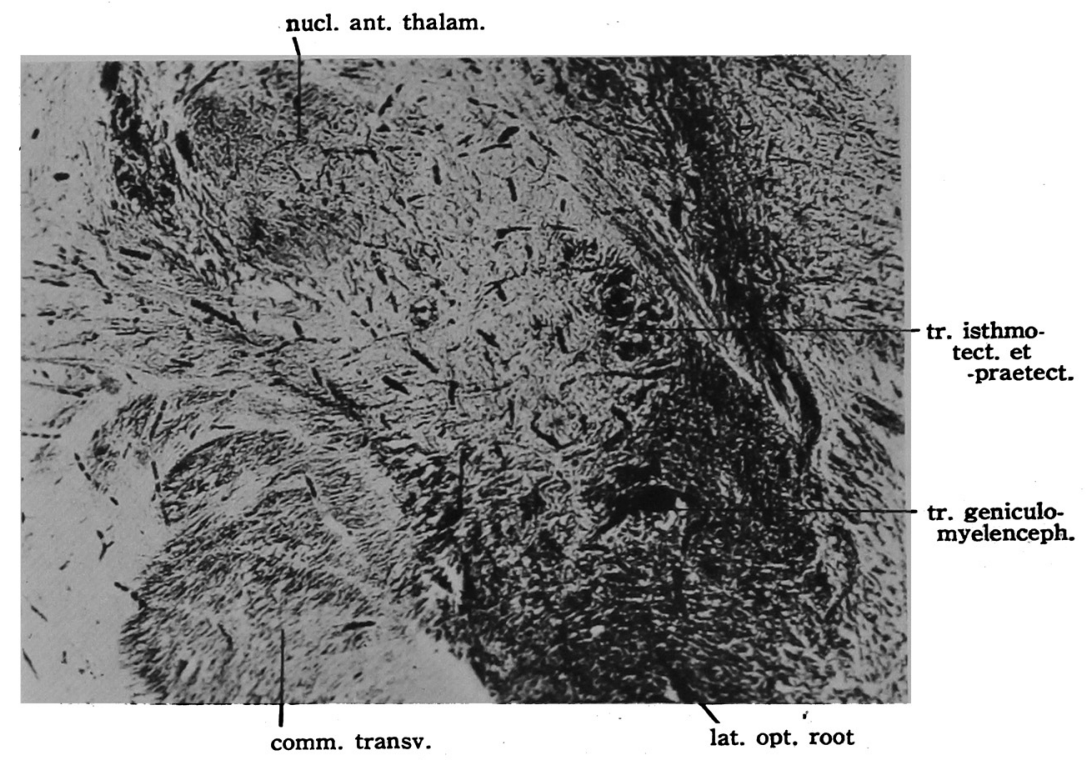

Fig. 16.

Photomicrograph of a transection from Cyprinus carpio, through the nucl. anterior thalami, showing the tr. geniculomyelencephalicus of Holmgren.

and intersects with the caudal segment of the commissura transversa in the "stratum zonale" of torus semicircularis of Mayser.

\section{The fibers in the fibrillar paratransversal area.}

This area is, for the most part, composed of the fiber groups of the tr. tubero-dorsalis as before noticed in this paper. Besides, there are several noticeable fiber bundles which take up an element of the paratransversal area as follows.

1) The fibers from the hypothalamus, or the nucleus praerotundus to the torus semicircularis.

The fine medullated fibers which probably arise in the various parts of the hypothalamus of the same side stream dorso-laterally showing a coarse, convexed curvature. They terminate immediately or mediately in the torus semicircularis, but it contains no commissural fibers in it.

2) A fiber bundle which achieves the component of the paratrans. versal area arises in the subhabenular region, accurately at the lateral region of the fasciculus descendens of Brickner (Fig. 6). This bundle 
is firstly consisted of the fine, lightly medullated fibers from the fibrae tectales n. optici or the fasciculi a tecto in nucleum ventralem of Brickner, ${ }^{1)}$ though the origin of this bundle is as yet unable to be ascertained with certainty. Caudally, the size of the bundle is considerably strong by the addition of fibers which relate with the fasciculus descendens, and then it changes its course ventro-laterally; being apart from the latter fascicle.

In the more caudal tracement of the transection, this bundle takes the sagittal course in the medial zone of the commissura transversa, lying on the juncture between the torus semicircularis and the lobus lateralis, or direct dorsal to the nucleus paraentopeducularis of Brickner ${ }^{2)}$ (Figs. 17 and 18).

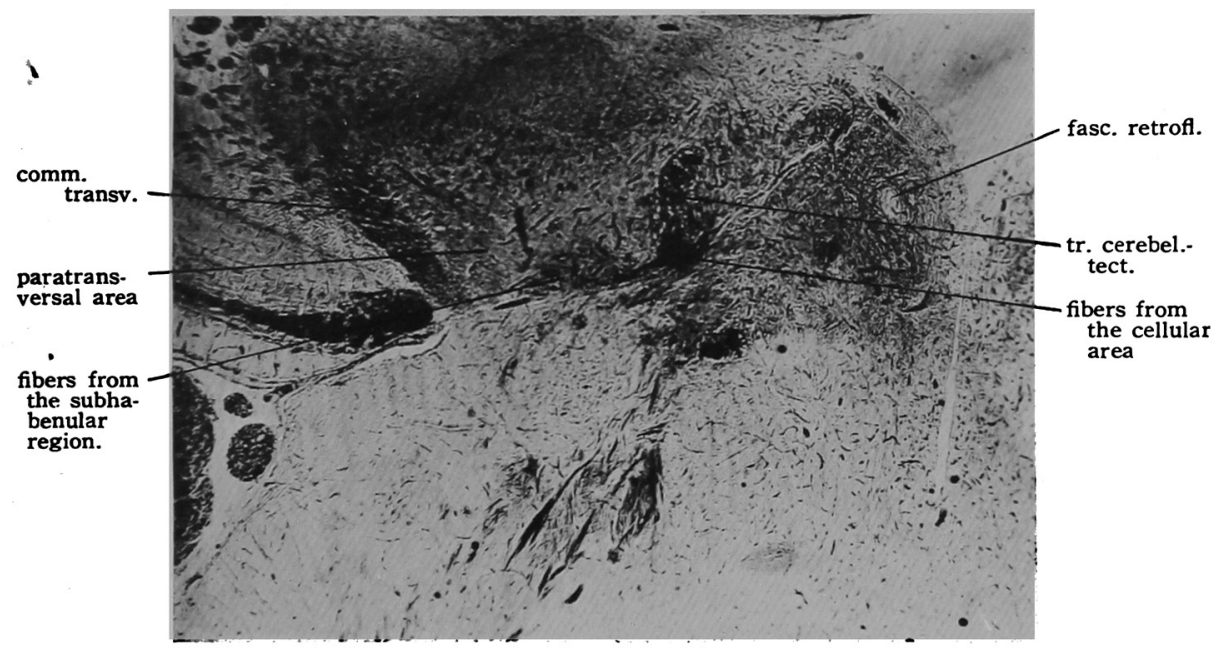

Fig. 17.

A transverse section from Cyprinus carpio, through the nucl. para-entopeduncularis of Brickner, showing the fiber bundle which achieves the component of the paratransversal area.

In the niveau of the caudal pole of the nucleus rotundus, this fiber bundle, for a while, gets back and soon ascends dorso-laterally with the slightly medullated fibers which probably emerge from the cell group around the tr. cerebello-tectalis, and finally enters the paratransversal area with the further dorsolateral direction in that area of torus semicircularis.

1) Brickner, R. M., 1929, pp. 264-265.

2) Brickner, R. M., 1929, p. 231. 


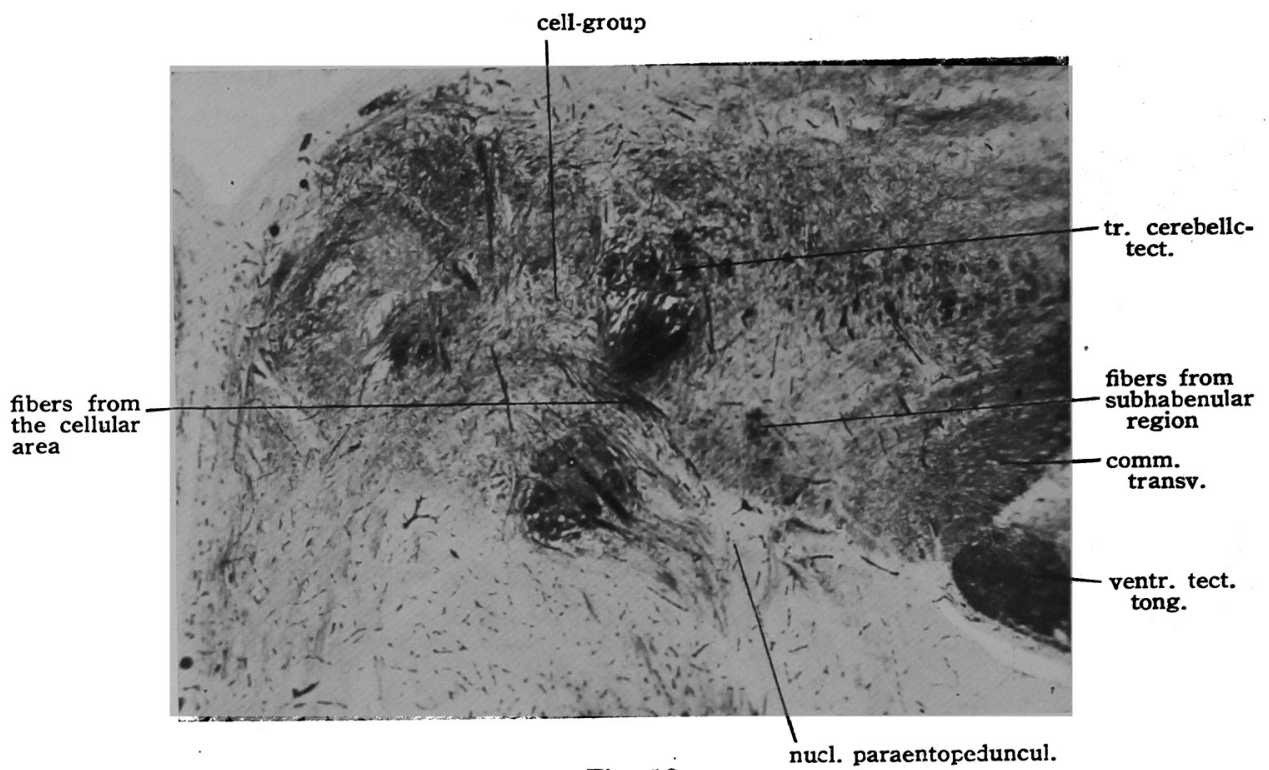

Fig. 18.

Photomicrograph of a transection from Cyprinus carpio, through the caudal pole of the nucl. rotundus, showing the fibers which achieve the component of the paratransversal area.

3) In the caudal segment of the above-described bundle or at the point where the tr. cerebello-tectalis meets with the ascending fibers of the comm. horizontalis, the fine, well-myelinated fibers stream from the cell group which are arranged in the medial and ventral area of the $t$. cerebello-tectalis (Fig. 17). One part of this fiber bundle runs from medio-dorsal to ventrolateral and enters the paratransversal area of the torus seinicircularis and the others descend ventro-laterally into the lobus lateralis and the nucleus para-entopeduncularis of Brickner.

\section{Nuclei which have the direct relation with the components of the commissura transversa or its collaterals.}

\section{1) Torus semicircularis Halleri.}

This portion has a prominent extension, projects dorsally and ranges sagittally between the caudal niveau of the praetectal area and that of the entrance of the cerebellum under the tectum opticum, having the well developed valvula cerebelli between the tori of both sides. The 
superficial, subepithelial zone of this part is composed of the lightly coloured nonfibrillar plate, whereas the inner part is filled up with the small and medium sized cells which are imbedded in the meshes of the fiber-nets. So, this part .presents as if it is a large ganglion as suggested by Mayser."

This part has a direct intirnate relation with the commissura transversa, besides it is an important area as the endstation of the most part of the fasciculus longitudiualis lateralis. The description of Frits $\mathrm{Ch}^{2}$ ) that the fibers of the ventral optic root are connected with this region is unable to be ascertained as shown by Mayser. ${ }^{3)}$ Some of the tr. tecto-bulbaris apparently pass through this area together with the fibers of the fasciculus longitudinalis lateralis as mentioned by Mayser. ${ }^{4}$ The distinct paths of the tr. tecto-bulbaris cruciatus et non-cruciatus and the tr. tecto-isthmicus are already described by many authors. The other fiber bundles which were described in the chapter of the paratransversal area have directly or indirectly to do with this part and also with the commissura transversa. ${ }^{5)}$

2) Segmentum internum thalami of Brickner.6)

This body probably takes the similar significance as stated by Brickner in Gadus aeglefinus (Fig. 19). Frontally, this body occupies a narrow area between the sulcus subhabenularis and the sulcus medius of Brickner. ${ }^{7)}$ It, however, elongates with the latero-ventral enlargement and projects medially into the third ventricle.

This is a grayish coloured body in the Weigert-preparations which is loosely distributed with the small cells and the coarse fibers of the fasciculus a comm. transversa in segmentum internum. Further caudally, this part disappears in the dorso-medial summit of the dorsal thalamus at the points where the fasciculus retroflexus and the fasciculus descendens make contact with each other.

3) Nucleus tegmenti motorius dorsalis of Brickner. ${ }^{8)}$

This nucleus lies ventro-lateral to the comm. posterior and dorsolateral to the segmentum internum. The latero-ventral tongue of this

\footnotetext{
1) M ayser, P., 1881, p. 350 .

2) Fritsch, G., 1878, p. 64.

3) Mayser, P., 1881, p. 342 .

4) Mayser, P., 1881, p. 348 .

5) Mayser, P., 1881, p. 270.

6) Brickner, R. M., 1929, pp. 238-239.

7) Brickner, R. M. 1929, p. 240.

8) Brickner, R. M., 1929, pp. 243-247.
} 


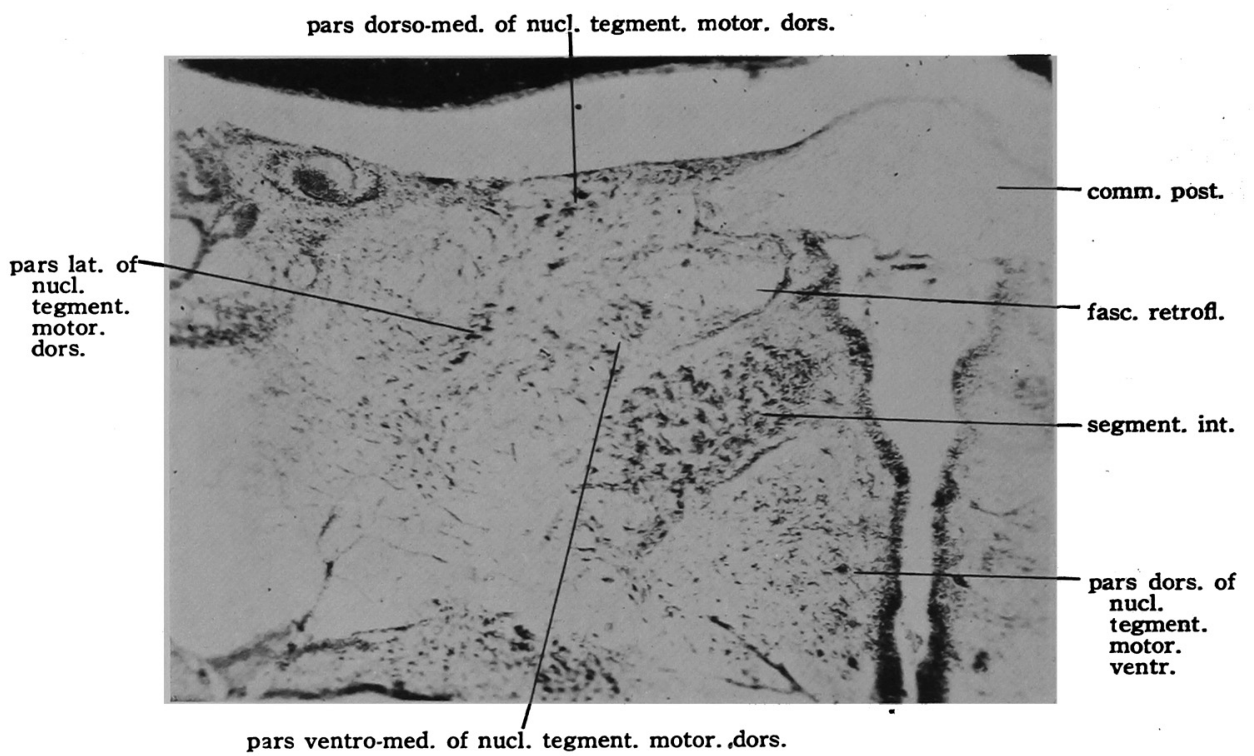

Fig. 19.

A transverse section from Carassius carassius, through the comm. posterior, showing the nucleus tegmenti motorius dorsalis of Brickner, and the segmentum internum thalami of Brickner.

body comes in touch with the caudal segment of the pars lateralis nc. praetectalis (comp. Figs. 22 and 23). It is a comparatively large, fibrillocellular body and also has an irregular, ovoid transection in the middle segment. This nucleus becomes increasingly narrower, until it vanishes almost in the same level where the segmentum internum disappears.

The arrangement of cells of this nucleus is somewhat varied from that of the Brickner's description. It can be separated into three groups of cells, such as the dorso-medial, ventro-medial and the lateral (Fig. 19).

The dorso-medial group: In the frontal segment of this nucleus, the small round and medium-sized spindle cells are situated rather laterally to the fasciculus retroflexus, imbedding in the fine fibrillar plexus. This part has possibly to do with the ventral group of fibers of the comm. posterior and somewhat well medullated fibers of the fasciculus retroflexus. More caudally, the cells of this part gradually transit dorsally and then dorso-laterally to continue to the lateral cell group, and become increasingly narrower and coarser in their distribution. This part, therefore, has the relation with the comm. posterior, the fasciculi a tecto in nucleum dorsalem $^{1)}$ and the fasciculi a tecto in commissuram posteriorem.

1) Brickner, R. M., 1929, pp. 247-258. 
The ventro-medial group: In the middle segment of this nucleus, the round, medium-sized and peach-shaped cells are distributed in a compact cluster at the ventral margin of this nucleus or the dorsal limiting area of the segmentum internum. The fibers of the tractus a nucleo dorsali in bulbum probably emerge from this region. A small number of the fasciculi a tecto in cormm. posteriorem pass through this area. Furthermore, this part is related to the fine fibers which descend from the nucleus tegmenti motorius ventralis or the lateral part of the fasciculus descendens.

The lateral group : The medium-sized cells seem to be transmitted from the above-mentioned two groups of cells and yet rather densely assembled. This part apparently stands in relation to the fasciculus a comm. transversa in nucl. dorsalem of Brickner, but the connection with the comypissura praetectalis of Edinger cannot be ascertained in this specimen.

4) Nucleus tegmenti motorius ventralis of Brickner. ${ }^{1}$

The greater part of this nucleus lies directly ventral to the segmentum internum, having estranged from each other by the sulcus medius, and the medial part of this nucleus faces at the third ventricle. The whole structure of this fibrillo-cellular body is almost similar to that of the Brickner's description.

This body is generally separated into two parts, such as the pars dorsalis and ventralis. The former is the fibrillar area, enveloping the small peach-shaped cells.

The vertical length of the whole body is rather stronger than that of the horizontal, and also the dorsal sphere is far broader than that of the ventral. This body caudally elongates with a gradual enlargment and the same with the segmentum internum. The medio-central column is compactly filled with the medium-sized cells, while the marginal area is coarsely distributed with somewhat large, peach-shaped cells. Especially, in the most caudo-ventral region of the pars ventralis, there are three or four large cells which are still obscure in their meaning (Fig. 20).

Frontal to the occurrence of the segmentum internum, the small cell cluster of the pars dorsalis extends ventrodorsally to the subhabenular area along the ventricular wall as described by Brickner.

The fiber connections correlated to this part have been fully explained by Brickner, ${ }^{2)}$ but, in any case, this part apparently has intimate relation with the comm. transversa (comp. Fig. 4).

1) Brickner, R. M., 1929, pp. 257-259.

2) Brickner, R. M., 1929, pp. 261-277. 


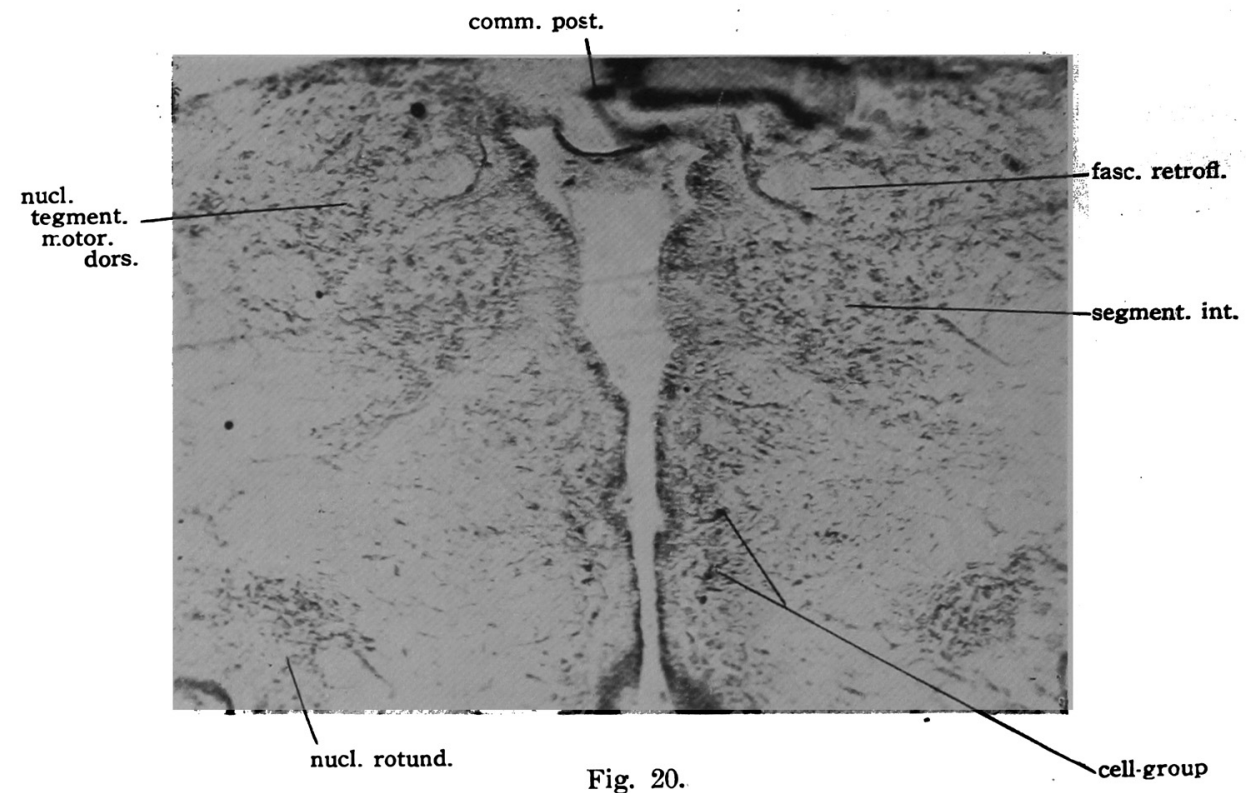

Fig. 20 .

A transverse section from Carassius carassius, through the caudal portion of the comm. posterior, showing the several large cells distributed in the pars ventralis of the nucl. tegmenti motorius ventralis of Brickner.

5) Periventricular cell-layer of the hypothalamus.

This area continuously extends from the pars ventralis of the nucleus tegmenti motorius ventralis along the ventricular wall ventralwards. The nuclei which have directly to do with the commissura transversa can be noticed as follows.

i) Nucleus anterior tuberis of Goldstein.'

Goldstein minutely described this nucleus in cyprinoids on its cellarrangement and fiber connection. The correlation between the comm. transversa and this nucleus is taken up by the tr. tubero-dorsalis as shown in the chapter of that tract.

ii) Nucleus lateralis tuberis.

This nucleus composed of considerably larger, fusiform or peachshaped cells superficially lies in the wall of the tuber and longitudinally elongates from the further medial commissuration of the commissura horizontalis to the most rostral segment of the recessus lateralis lobi inferioris.

As the connective fiber path of this nucleus, the afferent fiber path

1) Goldstein, K., 1905, r. 196. 
from the tr. strio-thalamicus was already noticed by $\mathrm{Haller} \mathrm{r}^{1)}$ and also the efferent fiber bundle was described by Goldstein.? Besides, this part may probably have to do with the tr. tubero-dorsalis of Goldstein.

iii) Nucleus ventricularis of the lobus medialis of Brickner.

This nucleus, composed of small, various-shaped cells lies dorso-medial zone of the lateral ventricular diverticulum. Lately, Brickner ${ }^{3}$ described the fasciculus a nucleo ventrali in ventricularem et tuberem anteriorem. But a small number of this fasciculus further elongate dorso-laterally to enter the paratransversal area.

\section{Nuclei which have a spatial relation with the comm. transversa in its origin or termination and also their correlation.}

\section{1) Praetectal nuclei.}

i) Corpus geniculatuum.

In the most frontal niveau of the praetectal region, this body is imbedded in the fronto-lateral optic root. It shows the characteristic twisted gray plate. The inost caudal part of this lies in the ventro-lateral area of the pars lateralis nucl. praetectalis or ventro-lateral edge of the nucleus anterior thalami.

ii) Nucleus anterior thalami.

In the transverse section, this nucleus can be noticed in the area medial to the corpus geniculatum. It begins to appear in the coarse fiber complexity of the fronto-medial optic root. This nucleus seems as the well developed ovoid ganglion as shown by many authors.

iii) Nucleus intermedius of Goldstein.

In the level of the vanishing of the corpus geniculatum, the most frontal part of the nucleus intermedius begins to appear in the fiber complication of the dorso-central area of the fronto-lateral optic root (Fig. 21). This part is composed of various cells of small round, spindle, and medium size, being imbedded in the fiber-plexus of the optic root. Caudally, it increases the number of cells and gradually transit dorsomedially. More caudally, this body ends in the somewhat lightly coloured, ventral area of the nucleus praetectalis (Cyprinus carpio).

\footnotetext{
1) Haller, B., 1898.

2) Goldstein, K., 1905, p. 197 .

3) Brickner, R. M., 1929, p. 269.
} 


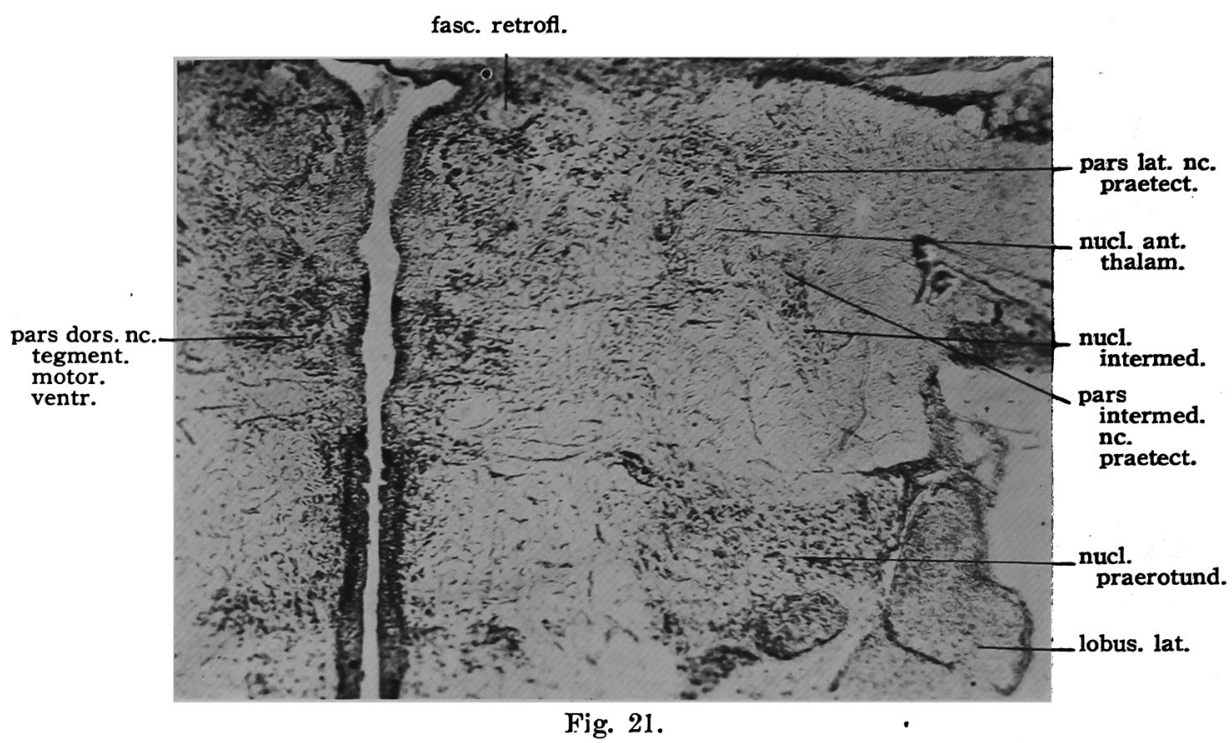

A transverse section from Carassius carassius, through the frontal segment of the nucl. anterior thalami, showing the nucl. intermedius of Goldstein.

iv) Nucleus praetectalis. ${ }^{1)}$

The large nucleus praetectalis comes in sight almost in the same niveau of the emergence of the nucleus intermedius. Firstly, the pars intermedia nc. praetectalis begins to appear.

a) Pars intermedia nc. praetectalis.

The cells of round and medium size are distributed in the direct dorsal area of the middle segment of the nucleus anterior thalami. This part elongates caudally with the gradual enlargement and intimately contacts with the dorso-lateral sphere of the nucleus anterior thalami (Fig. 21). More caudally, this part reduces its size, by and by, and then transits ventrolaterally, until it unites with the dorsal projection of the pars medialis nc. praetectalis between the nucl. anterior thalami and the pars lateralis nc. praetectalis (Fig. 22).

b) Pars medialis nc. praetectalis.

This body is slightly varied from that of Ophicephalus argus Cantor ${ }^{2)}$ in its appearance, so that the acellular gray matter of this body begins to appear between the nucl. anterior thalami and the ventral tectum

1) This nucleus may perhaps correspond to the corpus geniculatum posterius of $R$. G. Meader, which is composed of a pars lateralis, ventralis and a pars dorsalis. Comp. Meader, R. G., 1934, p. 27.

2) Kudo, K. and Suzuki, N., 1934. 
tongue almost in the same niveau where both of the nucleus intermedius and the pars intermedia nc. praetectalis respectively come in sight, showing

pars lat. nc. praetect.

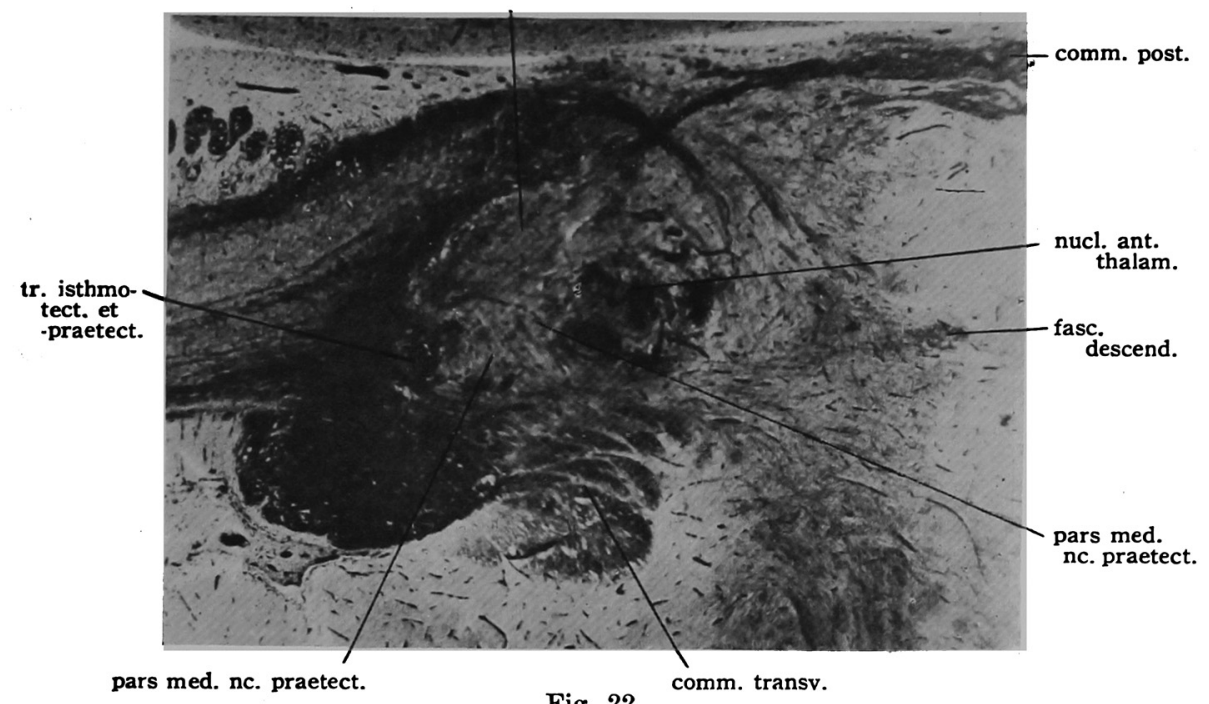

Fig. 22.

$\Lambda$ transverse section from Cyprinus carpio, through the comm. posterior, showing the praetectal nuclei.

a flatt cuneiform in transection. Then, this body gradually elongates caudally piercing the space among the nucleus anterior thalami, the ventral tectum tongue and the frontal segment of the pars lateralis nc. praetectalis (Fig. 22). More caudally, this body becomes increasingly narrower, until it disappears in the sarne level or the direct ventro-medial edge of the pars lateralis nc. praetectalis.

c) Pars lateralis nc. praetectalis.

This fibrillo-cellular body shows the greatest enlargement among these three parts of this nucleus and lies in the direct frontal part of the ventral tectum tongue, lateral to the nucleus anterior thalami, showing an ovoid transection with the diagonal axis from dorso-medial to ventro-lateral (Figs. 21, 22 and 23).

The more caudal segment of this body lies just under the lateral arm of the comm. posterior. The small round cells are somewhat loosely distributed in the medio-ventral zone of this body, whereas the mediumsized cells are arranged in the dorso-lateral sphere.

v) Nucleus corticalis.

This nucleus cannot be ascertained in this specimen. 


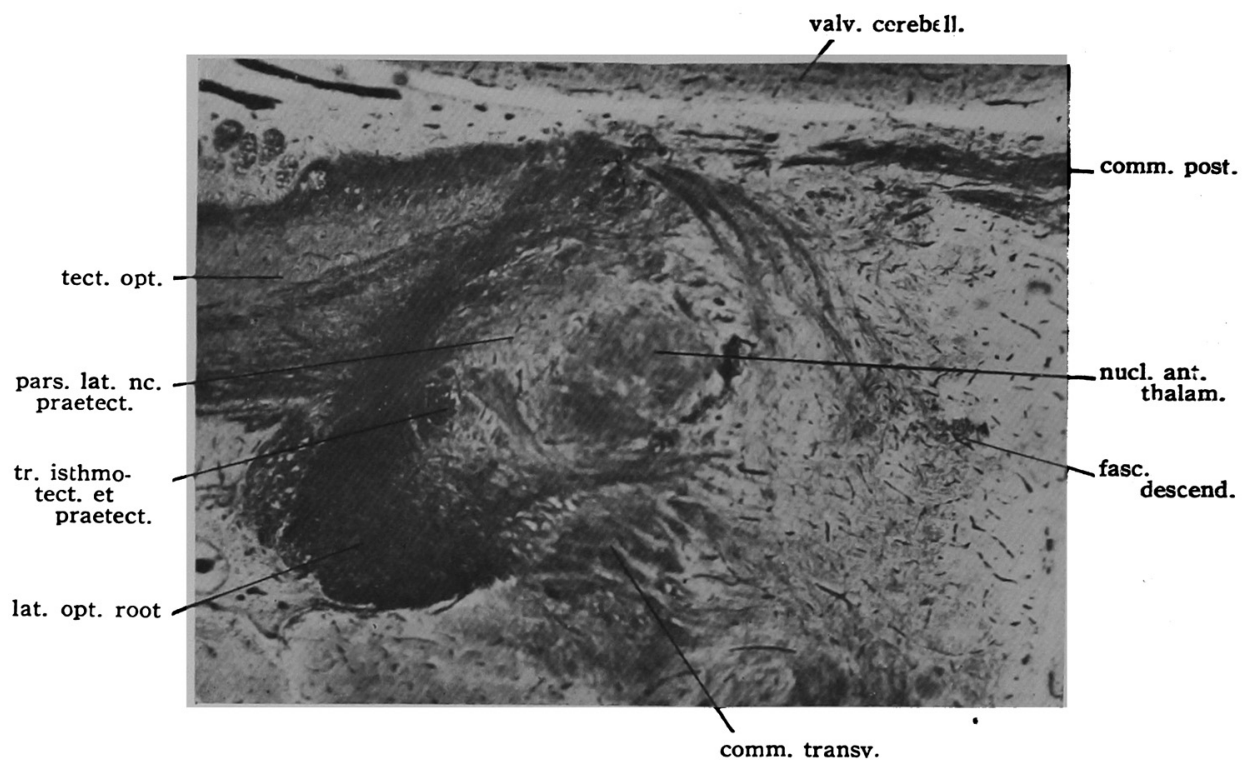

Fig. 23.

A transverse section from Cyprinus carpio, through the praetectal region, especially the pars lateralis nc. praetectalis.

vi) The lightly coloured segment of the medial area of the pars intermedia nc. praetectalis.

In the medial area of the pars intermedia nc. praetectalis, there is lightly coloured area being loosely distributed with the very fine fibers and densely surrounded by the well-medullated fibers. 'This part apparently indicates an independent nucleus, but still its correlation must be ascertained by the further investigation.

\section{2) Nucleus praerotundus.}

At the level of the rostral margin of the lateral lobes, this nucleus appears inmediately ventro-lateral to the commissura transversa and consists of a fairly compact mass of irregularly shaped cells of medium size (Fig. 24). The frontal portion of this nucleus is certainly related to the nucleus transversus of $\operatorname{Franz}^{\mathrm{i})}$ and also the nucleus praerotundus of Harry Bergquist.") From this point this body extends caudo-mesially to the upper region of the corpus mamillare, enveloping rentrally the

1) Franz, V., 1912, p. 433.

2) Bergquist, H. 1932, p. 213. 


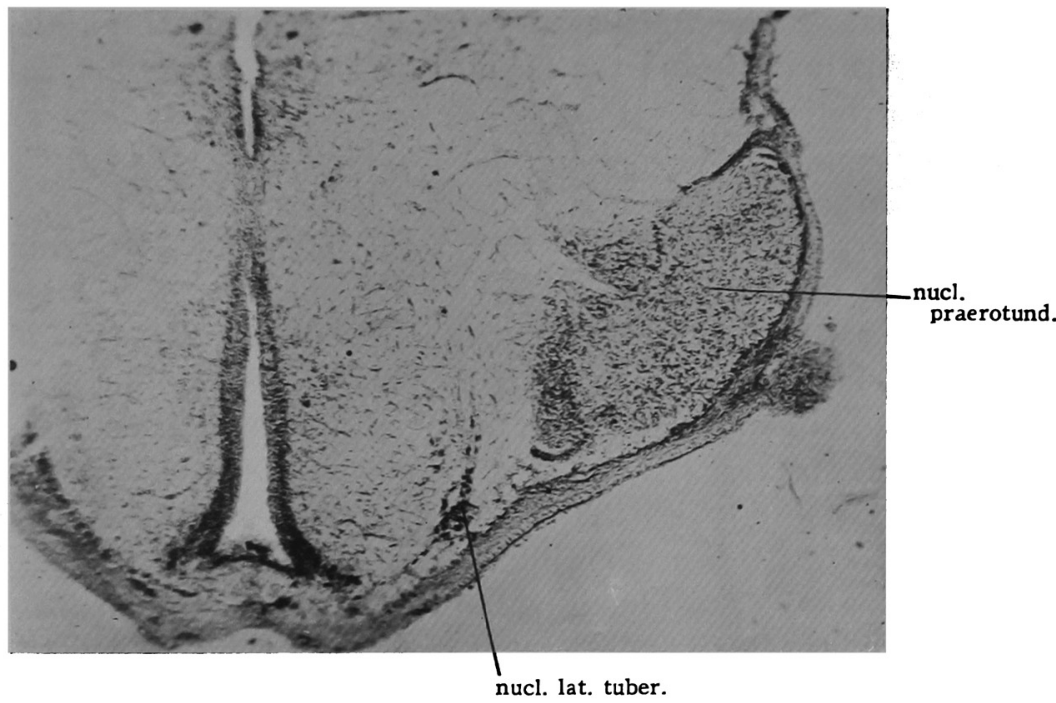

Fig. 24.

A transverse section from Carassius carassius, through the medio-frontal segment of the diencephalon, showing the nucl. praerotundus.

núcleus rotundus proprius Goldstein as shown by Holmgren, ${ }^{1)}$ Goldstein") and Sheldon. ${ }^{3)}$ The caudal part of this nucleus continues to the corpus mamillare of Goldstein or the nucleus supramamillaris of H. Bergquist.) This nucleus obviously has intimate connection with the paratransversal area and the spatial connection with the fibers which arise in the periventricular zone of the hypotbalamus and yet extend to the paratransversal area. Furthermore, a slight fibrillar component of the commissura transversa probably arises or ends in this nucleus as mentioned by Franz. ${ }^{5)}$

3) Nucleus para-entopeduncularis of Brickner. ${ }^{6)}$

It lies just frontal to the nucleus rotundus Fritsch, in the dorsal part of the lateral hypothalamic lobe as shown by Brickner. This is a rather small, very well-defined body with small various-sized cells.

Brickner distinguished the three large connections, such as the good proportion of the tractus lobo-bulbaris of Mayser and of C. J. Herrick, the large portion of the tr. olfacto-hypothalamicus medialis and

1) Holmgren, N., 1920, p. 2 s2.

3) Sheldon, R. E., 1912, p. 202.

5) Franz, V., 1912, p. 434.
2) Goldstein, K., 1905, p. 241.

4) Bergquist, H., 1932, p. $21: 3$.

6) Brickner, R. M., 1932, pp. 231-233. 
the tr. a para-entopedunculari in partem anteriorem. But the relation between this nucleus and the fibers of the paratransversal area is missed in his description.

\section{4) Lobus inferior. ${ }^{1)}$}

The gross anatomy of this part is repeatedly studied by many authors. This part is generally distributed with the small cells, especially in the peripheral portion of the lobi laterales, while the inner part is coarsely arranged with rather larger, various-shaped cells forming the nucleus diffusus lobi lateralis of Goldstein or the substantia grisea lobi inferioris of Ariëns Kappers. This body which is quite well defined in cyprinoids has indirectly to do with the commissura transversa, and especially with the paratransversal area, showing the spatial fibrillar connections between them such as the fasciculus a nucleo ventrali in hypothalamum, tractus a segmento interno in hypothalamum and the tr. geniculo-hypothalamicus.

5) Cell-groups around the tr. cerebello-tectalis.

At the point where the ascending thick fiber bundle of the comm. horizontalis, after it has passed the nucleus rotundus Fritsch, meets with the azygous thick bundle of the tractus cerehello-tectalis, the rather large, spindle and also small round cells are assembled, respectively in the medial and the lateral area (Fig. 25). The well-myelinated fibers emerge from the medial large-cell group and run ventro-laterally along the limiting zone between the torus semicircularis and the lobus lateralis and soon this fiber bundle runs dorso-laterally into the paratransversal area as before described in this paper (Fig. 17). Some of these fibers stream ventro-laterally into the nucleus para-entopeduncularis (Fig. 18).

More caudally, the fine, slightly medullated fibers arise in the lateral, small-round-cell group and they also enter the paratransversal area in the similar destination with the above-mentioned fiber bundle.

6) Ganglion isthmi.

This is well-defined ovoid body lying in the direct medial zone of the junction between the torus semicircularis and the bulb. The longitudinal axis of this body diagonally penetrates from dorso-lateral to ventro-medial. The medium-sized, round or spindle cells are irregularly distribued in this body. The fiber connections of this nucleus with the fasciculus longitudinalis lateralis, the bundle which ascends from the

1) Suzuki, N., 1932. 
oblongata or the bundle $\mathrm{X}$ of Mayser, tectum opticum and the nucleus praetectalis have respectively been mentioned by many authors. Further-

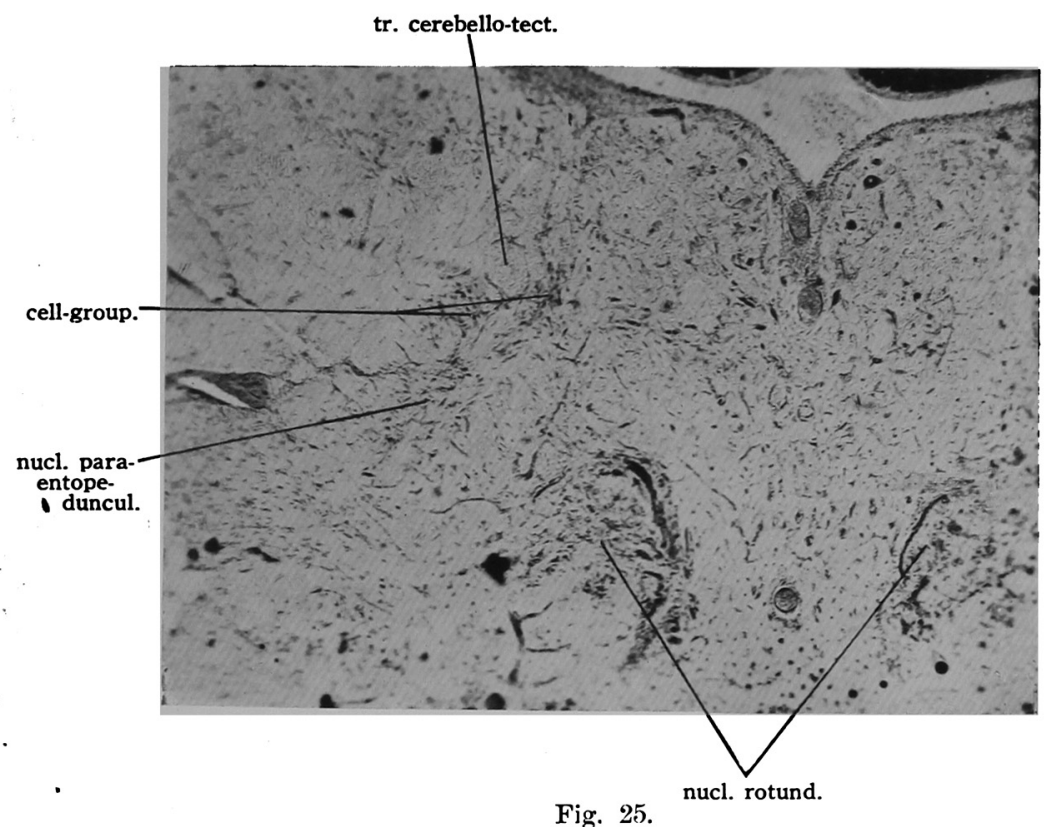

Fig. 25.

A transverse section from Carassius carassius, through the caudal pole of the nucl. rotundus, showing the cell-groups around the tr. cerebello-tertalis.

more, the direct connection hetween this body and the commissura transversa is obscure in this specimen.

7) Medial cell-group of bulb (Holmgren) or the endstation of the tr. geniculo-myelencephalicus.

The acellular gray mass lies under the fasciculus longitudinalis posterior in the ventral half of the bulb. This body begins to appear in the direct caudal plane of the ganglion interpedunculare and stands collateral to the raphe. This body elongates more caudally being surrounded by the fiber plexus and covered dorso-laterally, by the rather large cells of the "ventrales Kerngebiet" of Haller." The final termination of the tr. geniculo-myelencephalicus cannot be ascertained in this specimen as shown by Holmgren in Callionymus lyra."

1) Haller, B., 1898.

2) Holmgren, N., 1920, p. 225. 


\section{Literature cited.}

Ariëns Kappers, C. U., Vergleichende Anatomie des Nervensystems der Wirbeltiere und des Menschen. II. Abschnitt. Haarlem. 1921.

Brickner, R. M., A description and interpretation of certain parts of the teleostean midbrain and thalamus. Jour. Comp. Neur., vol. 47, no. 2, 1929.

Bergquist, H., Zur Morphologie des Zwischenhirns bei niederen Wirbelthieren. Acta zool., 1932.

Fritsch, G., Untersuchungen über den feineren Bau des Fischgehirns. Berlin, 1878.

Franz, V., Beiträge zur Kenntnis des Mittelhirns und Zwischenhirns der Knochentische. Folia neurobiol., Bd. 6, 1912.

Goldstein, K., Untersuchungen über das Vorderhirn und Zwischenhirn einiger Knochenfische, nebst einigen Beiträgen über Mittelhirn und Kleinhirn derselben. Arch. f. mikr. Anat. und Entw.-Ges., Bd. 66, 1905.

Haller, B., Vom Bau des Wirbelthiergehirns. I. Theil. Salmo und Scyllium. Morph. Jahrb., Bd. XXVI, H. 3 u. 4, 1898.

Holmgren, N., Zur Anatomie und Histologie des Vorder- und Zwischenhirns der Knochenfische. Acta zool., 1920.

Jansen, J., A note on the optic tract in teleosts. Proceedings of Kon. Akad. v. IVetensch. Amsterdam, vol. XXXII, no. 8, 1929.

$\mathrm{K}$ udo, K., Contributions to the knowledge of the brain of bony fishes. Proceedings of Kon. Akad. v. Wetensch. Amsterdam, vol. XXVI, nos. 1 and 2. 1923.

Kudo, K. und Suzuki, N., Über die Commissura transversa bei Ophicephalus argus Cantor. Psychiatrische en Neurologische Bladen, Jg. 1934, no. 3 en 4.

Masser, P., Vergleichend anatomische Studien über das Gehirn der Knochenfische mit besonderer Berücksichtigung der Cyprinoiden. Zeitschr. f. wiss. Zool.. Bd. 36, H. 2, 1881 .

Meader, R. G., The corpus geniculatum and associated nuclei in the brains of hony fishes. Jour. Comp. Neur., vol. 58, no. 4, 1934 (Supplement).

Sheldon, R. E., The olfactory tracts and centers in teleosts. Jour. Comp. Neur., vol. $22,1922$.

Suzuki, N., On the nucleus rotundus Fritsch in teleosts. Annual Report of the Work, Sendai, Japan, no. 8, 1932. (The Saito Gratitude Foundation)

Suzuki, N., On the nerve fibre systems of the lobi inferiores in the brain of Salmonidae. Ibidem.

\section{Supplementary note.}

At the time of the proof-reading of this press, I read the original paper of R.G. Meader, most recently published (Jour. Comp. Neur., vol. 60, no. 3, 1934). According to his description in Holocentrus, the tripartition of the nucl. praetectalis in my report somewhat differs from that of the corpus geniculatum posterius of Meader. The details of this account, however, will be reserved for some future occasion.

Mukden, N. Suzuki. 